\title{
7 Bilateral and Multilateral Financing of HIV/AIDS Programs: The World Bank, the International Monetary Fund, the Global Fund, Bilateral Donors and the Private Sector
}

\begin{abstract}
"While much of the surge in HIV funding is attributable to a highly successful lobby including UNAIDS, some results from donor frustration at the lack of reform in government organisations. At least, donors say, we can save some lives through investing directly in prevention and treatment. Unfortunately, disease-specific funding such as that for HIV is making things worse by creating policy, programming and financing in parallel with those for basic health services. Funding for preventing mother-to-child transmission, for example, is not strengthening maternal and child health services including antenatal care, where the testing of pregnant women must become part of normal business if transmission is to be reduced. More-over, there are opportunity costs: high spending on HIV is attracting staff away from other programmes."
\end{abstract}

Veronica Walford, August 14, Financial Times

This chapter examines the operations of the World Bank (a multilateral development institution), the International Monetary Fund (a multilateral financial institution) and the Global Fund to Fight AIDS, Tuberculosis and Malaria (a multilateral fundraising and financing institution) to fight HIV/AIDS. We also examine the role of bilateral donors and the private sector in financing the fight against HIV/ AIDS. We examine the relationships among bilateral donors and international organizations, what distinguishes their roles in the global HIV/AIDS pandemic and the extent to which their activities overlap. In addition, we consider how funding strategies and parameters may affect the effectiveness of AIDS funding in preventing transmission and providing treatment.

\subsection{Overview of HIV/AIDS Funding}

During the past two decades, funding has grown exponentially - especially since 2001. In 1986, global donor funding for HIV/AIDS was less than one million US dollars. By 2007, the funding had grown to USD 10 billion. As Fig. 7.1 shows, the three largest donors are the US President's Emergency Plan for AIDS Relief (PEPFAR), the Global Fund to Fight AIDS, Tuberculosis and Malaria, and the World Bank Multi-Country HIV/AIDS Program for Africa (MAP), in that order. The activities of PEPFAR are analyzed in Chap. 8. Figure 7.2 charts the growth of total annual resources available over this period of time. Figure 7.3 projects the funding required to achieve universal access by 2015 . 


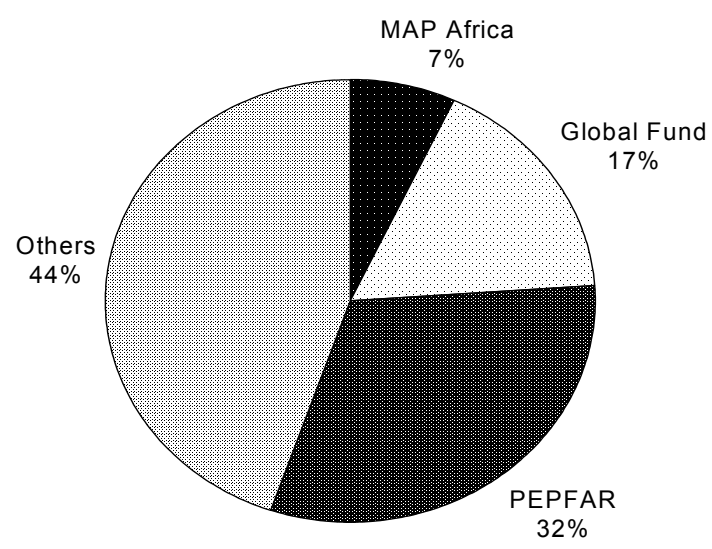

Fig. 7.1 Global funding for HIV/AIDS. Source: Oomman et al. (2007)

Total Annual Resources Available 1986-2007

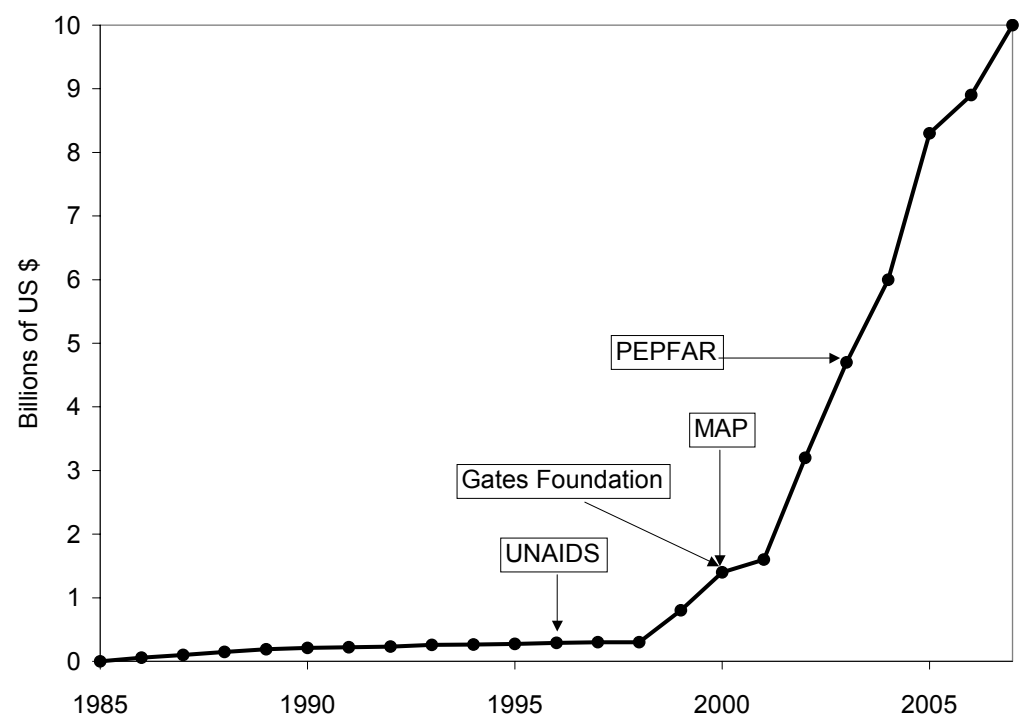

Fig. 7.2 Flow of resources to combat HIV/AIDS 1986-2007. Source: Financial resources required to achieve universal access to HIV prevention, treatment, care and support, UNAIDS, 26 September, 2007 
Scenarios towards "Universal Access" in 132 countries, 2007-2015 (US $\$$ billion)

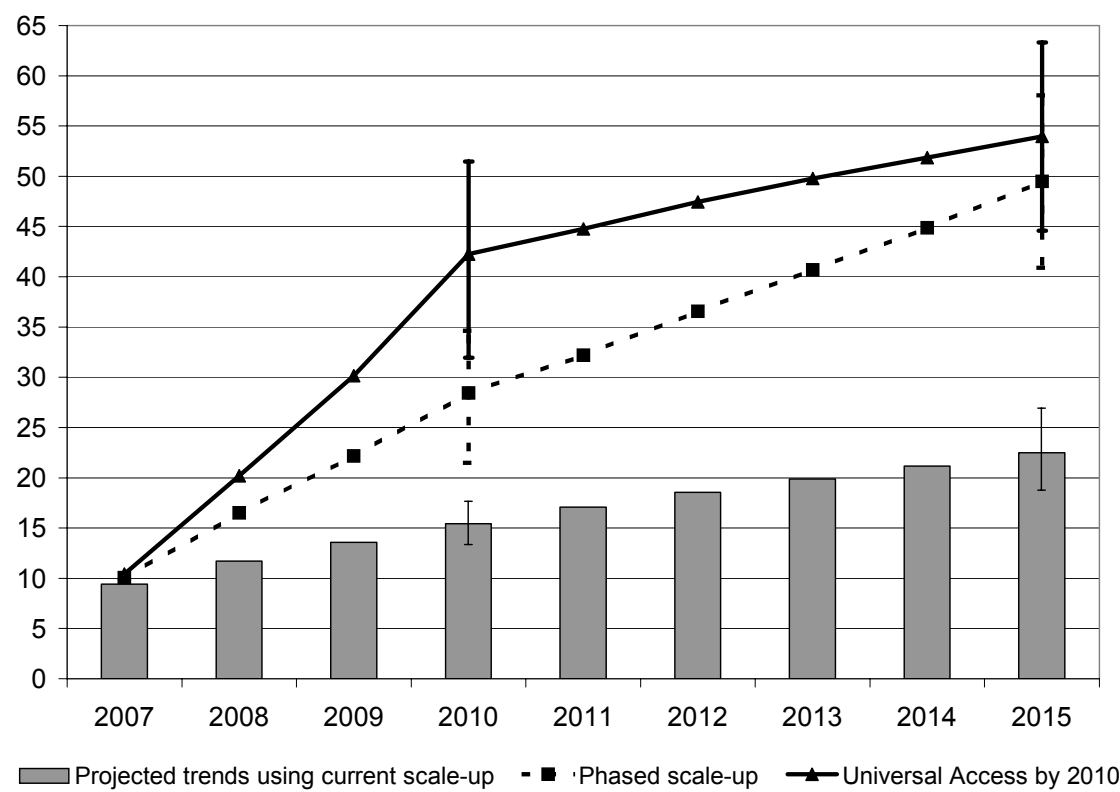

Fig. 7.3 Scaling up towards universal care. Source: financial resources required to achieve universal access to HIV prevention, treatment, care and support, UNAIDS, 26 September, 2007

The following series of Tables (7.1-7.7) show the funding requirements for HIV/AIDS and break down those requirements by area in which the funding is needed. Table 7.8 contrasts the actual funding available and the funding gap. (In Chap. 4, we considered the potential economic impact on recipient countries of achieving HIV/AIDS funding requirements).

Table 7.1 AIDS funding requirements for low- and middle-income countries in USD billion

\begin{tabular}{lrrrc}
\hline Item & 2006 & 2007 & 2008 & 2006-2008 \\
\hline Prevention & 8.4 & 10.0 & 11.4 & 29.8 \\
Care and treatment & 3.0 & 4.0 & 5.3 & 12.3 \\
Support for orphans & 1.6 & 2.1 & 2.7 & 6.4 \\
Program costs & 1.5 & 1.4 & 1.8 & 4.6 \\
Human resources & 0.4 & 0.6 & 0.9 & 1.9 \\
Total & 14.9 & 22.1 & 55.1 & 18.1 \\
\hline \multicolumn{4}{c}{ Source: UNAIDS }
\end{tabular}


Table 7.2 Funding required for prevention

\begin{tabular}{|c|c|c|c|}
\hline Prevention activities & $2006-2008$ & 2007 & 2008 \\
\hline Universal precautions & 5,838 & 1,944 & 2,303 \\
\hline Safe injections & 2,690 & 897 & 897 \\
\hline Post-exposure prophylaxis & 5 & 2 & 2 \\
\hline Blood safety & 685 & 228 & 231 \\
\hline Prevention of mother-to-child transmission & 794 & 264 & 324 \\
\hline Improving management of STI & 2,154 & 718 & 764 \\
\hline Condom provision & 4,506 & 1,501 & 1,625 \\
\hline Condom social marketing & 525 & 175 & 190 \\
\hline Special populations & 654 & 252 & 252 \\
\hline Prevention programs for people with HIV & 103 & 33 & 48 \\
\hline Workplace & 1,573 & 523 & 628 \\
\hline Programs for injecting drug users & 443 & 149 & 180 \\
\hline Programs for men who have sex with men & 1,218 & 407 & 499 \\
\hline Programs on sex workers and clients & 1,663 & 552 & 682 \\
\hline Youth out of school & 2,838 & 945 & 1,126 \\
\hline Youth in school & 313 & 104 & 108 \\
\hline Voluntary counseling and testing & 1,710 & 569 & 690 \\
\hline Community mobilization & 1,830 & 608 & 772 \\
\hline Mass media & 299 & 100 & 109 \\
\hline Total & 29 & 11 & 840 \\
\hline
\end{tabular}

Table 7.3 Funding required for treatment and care to achieve the coverage targets shown

\begin{tabular}{lccc}
\hline Year & $\begin{array}{c}\text { People on ART } \\
\text { (millions) }\end{array}$ & $\begin{array}{c}\text { ART coverage of urgent } \\
\text { cases (\%) }\end{array}$ & $\begin{array}{c}\text { Total Funding } \\
\text { (USD million) }\end{array}$ \\
\hline 2006 & 3.0 & 55 & 2,986 \\
2007 & 4.8 & 67 & 4,029 \\
2008 & 6.6 & 75 & 5,250 \\
2009 & 8.3 & 79 & - \\
2010 & 9.8 & 80 & - \\
\hline \multicolumn{4}{c}{ Source: UNAIDS }
\end{tabular}


Table 7.4 Distribution by activity of the funding required for treatment and care

\begin{tabular}{lrrc}
\hline Treatment and care (USD million) & 2007 & 2008 & 2006-2008 \\
\hline Palliative care & 302 & 295 & 905 \\
Provider initiated testing & 79 & 109 & 254 \\
Opportunistic infections treatment & 703 & 707 & 2,096 \\
Opportunistic infections prophylaxis & 403 & 510 & 1,200 \\
Antiretroviral therapy & 2,482 & 3,624 & 7,748 \\
Laboratory testing & 79 & 104 & 237 \\
Total & 4,048 & 5,349 & 12,440 \\
\hline
\end{tabular}

Source: UNAIDS

Table 7.5 Funding required for activities supporting orphans and vulnerable children

\begin{tabular}{lrrrr}
\hline Orphan support (USD million) & 2006 & 2007 & 2008 & $2006-2008$ \\
\hline Education & 193 & 287 & 443 & 923 \\
Health care and support & 145 & 174 & 200 & 519 \\
Family/home support & 971 & 1,255 & 1,604 & 3,830 \\
Community support & 14 & 18 & 25 & 57 \\
Organization costs & 246 & 322 & 422 & 990 \\
Total & 3,043 & 4,048 & 5,349 & 12,440 \\
\hline \multicolumn{5}{c}{ Source: UNAIDS }
\end{tabular}

Table 7.6 Funding required for program support and infrastructure support

\begin{tabular}{lrrc}
\hline Program activities (USD million) & 2007 & 2008 & 2006-2008 \\
\hline Management & 376 & 390 & 1,251 \\
Advocacy and communications & 111 & 111 & 340 \\
Monitoring and evaluation & 138 & 146 & 432 \\
Operations research & 7 & 7 & 25 \\
Training & 136 & 231 & 439 \\
Logistics and supply & 259 & 304 & 868 \\
Supervision and patient tracking & 68 & 92 & 257 \\
Drug resistance surveillance & 68 & 68 & 205 \\
Construction of new health centers & 23 & 167 & 250 \\
Infrastructure upgrading & 185 & 236 & 542 \\
Total & 1,371 & 1,753 & 4,610 \\
\hline \multicolumn{2}{c}{ Source: UNAIDS } & &
\end{tabular}


Table 7.7 Funding required for building human resource capacity

\begin{tabular}{lrcc}
\hline (USD million) & 2007 & 2008 & $2006-2008$ \\
\hline Education & 89 & 123 & 262 \\
Nurses' wage supplements & 261 & 370 & 784 \\
Doctors' wage supplements & 258 & 366 & 776 \\
Total & 608 & 859 & 1,822 \\
\hline \multicolumn{4}{r}{ Source: UNAIDS }
\end{tabular}

Table 7.8 Actual funding and funding gap

\begin{tabular}{lcc}
\hline Billions of US dollars & 2006 & 2007 \\
\hline Available resources & $\$ 8.9$ & $\$ 10$ \\
Funding gap (2005-2007) & At least \$18 billion & \\
\hline
\end{tabular}

Source: UNAIDS. Resource needs for an expanded response to aids in low and middle income countries. Presented to the Program Coordinating Board. Seventeenth Meeting, Geneva, 27-29 June 2005

While the increase in funding for HIV/AIDS is a positive development, the multiplicity of donors has created problems regarding overlapping actions and conflicting conditions attached to the aid. In 2005, over one hundred Ministers, Heads of Agencies and other Senior Officials endorsed the Paris Declaration on Aid Effectiveness, an international agreement to increase efforts in harmonization, alignment and managing aid for results with a set of monitorable actions and indicators (OECD 2005). Also in 2005, the UNAIDS Global Task Team on Improving AIDS Coordination Among Multilateral Institutions and International Donors (GTT) published a set of recommendations on how countries and multilateral institutions can streamline their AIDS-related activities. Many of these recommendations are aimed at improving the coordination of the AIDS-related activities of multilateral organizations and minimizing overlap. The recommendations build upon the principles of the "Three Ones" - the three principles for coordinated response at the country level: (1) one agreed HIV/AIDS action framework that provides the basis for coordinating the work of all parties; (2) one national AIDS coordinating authority, with a broad based multi-sector mandate; and (3) one agreed country level monitoring and evaluation system (UNAIDS 2005). According to a 2006 UNAIDS report, more than $40 \%$ of national AIDS plans were not serving as the framework for contributions by donors (UNAIDS 2006). More than $40 \%$ of national AIDS plans were not evaluated for cost or provided sufficient clarity on inputs and outputs, with the result that donors preferred to engage more directly with countries (Sidibe et al., 2006).

Poor alignment of donor strategies with national efforts and poor harmonization among donor procedures for aid management are significant impediments to achieving universal access to treatment for HIV/AIDS, because of the number and diversity of organizations that have become involved in addressing the pandemic. Duplication of work and high transaction costs by individual agencies, together 
with the absence of important learning exchanges, economies of scale and synergies, impedes the speed, quantity, and quality of the response to the pandemic (Sidibe et al., 2006). Thus, while pursuing affordable access to medicine and expanding medical services infrastructure are both essential elements for expanding access to treatment, they form a two-legged stool. The harmonization of donor and governance processes represents a key third element in the efforts to expand access to information and treatment.

Donald Kaberuka, President of the African Development Bank, has noted that in the late 1980s, 22 members of the Development Assistance Committee of the OECD (OECD/DAC) accounted for $95 \%$ of total aid to developing countries. Twenty years later, aid to developing countries is delivered through more than 150 multilateral agencies, 33 bilateral members of the OECD/DAC and at least 10 non-DAC governments. As a result, some developing countries have more than 700 active projects and receive more than 400 missions a year, each with its own specific requirements. In theory, this proliferation of donors should bring new perspectives, more resources, greater innovation and competition, which could reduce costs and improve program delivery. However, this has not been the result thus far (Kaberuka 2007). Figure 7.4 shows the sources of the estimated and projected funding for the AIDS response from 2005 to 2007.

In this regard, national leadership in recipient countries is important for ensuring a coordinated, multi-sectoral approach (that is, coordination across several government ministries, not just the health ministry) (Patel 2004). However, even where the host government has donor coordination mechanisms in place, coordination is made more difficult when individual donors come with pre-established priorities, without involving host countries in the setting of priorities (Dekay 2004). One clear example is PEPFAR. It has established abstinence-only as a priority, and denied funding for needle exchange programs, which are priorities for the US government that do not necessarily coincide with the priorities of host governments (see Chap. 8 for details).

In addition to the multiplicity of players, donors and host governments with different interests, ideologies, demands and expectations make coordination more difficult for host countries. When donors are driven by their own national ideologies and interests, at the expense of scientifically proven approaches, they undermine coordination and local leadership. Moreover, when donors focus on civil society, they may undermine adherence to a national HIV/AIDS framework (Mwale 2004).

There has also been a proliferation of recipients. Figure 7.5 shows the distribution of entities that participated in the preparation of funding proposals for Round Four of the Global Fund.

With respect to the lack of donor coordination, some argue that the source of the problem is the host government, which may fear losing control over the agenda to a well-coordinated group of donors, rather than the donors themselves. 
Estimated and Projected Funding

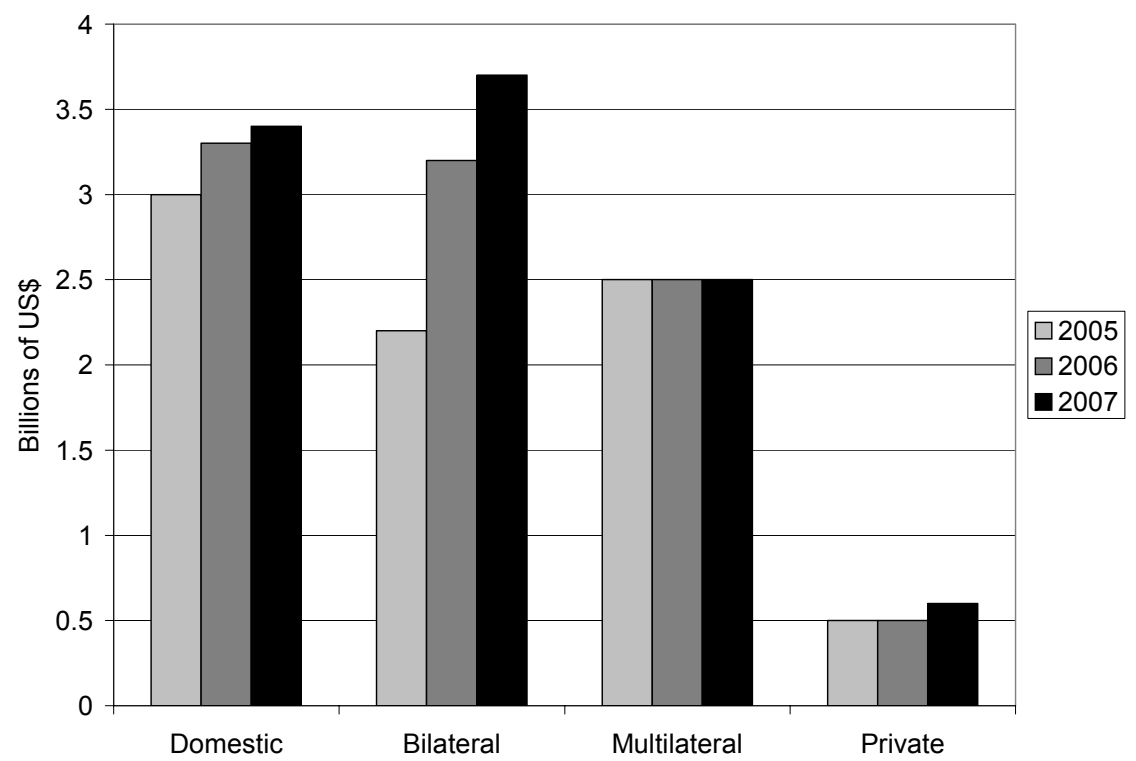

Fig. 7.4 Sources of the estimated and projected funding for the AIDS response from 2005 to 2007. Source: UNAIDS

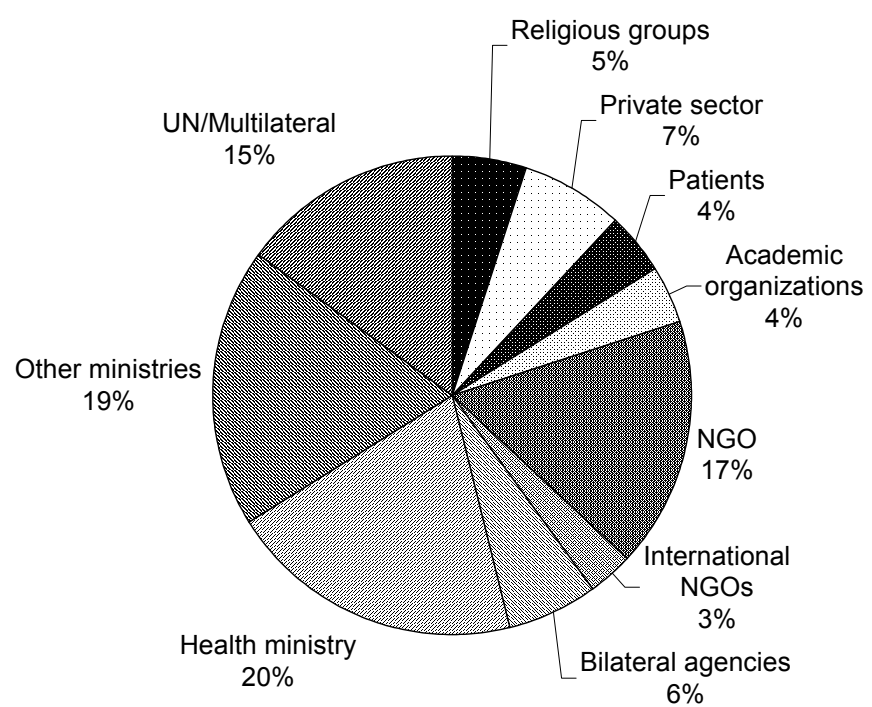

Source: The Global Fund to Fi_ht AIDS, Tuberculosis and Malaria

Fig. 7.5 Country coordinating mechanisms: entities participating in preparation of round four proposals. Source: Global Fund 
Donor commitments and disbursements can diverge. Table 7.9 shows that, in the case of some bilateral donors, commitments have exceeded disbursements, while for others the reverse is true. In most cases, the actual disbursements lag commitments (OECD 2006).

Table 7.9 Bilateral commitments and disbursements of DAC members in 2004 (USD Millions)

\begin{tabular}{|c|c|c|c|c|}
\hline Country & $\begin{array}{c}\text { Bilateral } \\
\text { commitments }\end{array}$ & $\begin{array}{l}\text { Imputed multilateral } \\
\text { commitments }\end{array}$ & $\begin{array}{c}\text { Total HIV } \\
\text { commitments }\end{array}$ & $\begin{array}{c}\text { Bilateral } \\
\text { disbursements }\end{array}$ \\
\hline Australia & 3.7 & 12.2 & 15.9 & 22.8 \\
\hline Austria & 1.2 & 3.6 & 4.8 & 0 \\
\hline Belgium & 30.4 & 21.4 & 51.8 & 11.5 \\
\hline Canada & 134.3 & 26.2 & 160.4 & 73.6 \\
\hline Denmark & 9.2 & 22.7 & 31.9 & 5.4 \\
\hline Finland & 4.7 & 7.3 & 12 & \\
\hline France & 11.1 & 135.3 & 146.4 & 3.6 \\
\hline Germany & 84.5 & 35.9 & 161.3 & 27.1 \\
\hline Greece & 0.6 & 2.1 & 2.7 & 0.6 \\
\hline Ireland & 5.8 & 5.5 & 11.3 & 5.8 \\
\hline Italy & 2.4 & 16.9 & 19.3 & 3.6 \\
\hline Japan & 3.1 & 86.8 & 83.7 & 7.3 \\
\hline Luxembourg & 3.6 & 2.1 & 5.7 & 3.8 \\
\hline Netherlands & 90.5 & 83.6 & 174.1 & 50 \\
\hline New Zealand & 0.7 & 1.4 & 2.1 & 0.6 \\
\hline Norway & 15.4 & 42.7 & 58.1 & 27.4 \\
\hline Portugal & 0.1 & 2.1 & 2.2 & 0.1 \\
\hline Spain & 7.5 & 23.1 & 30.6 & 7.5 \\
\hline Sweden & 58.2 & 52.9 & 111.1 & 46.5 \\
\hline Switzerland & 7.8 & 10 & 17.7 & 6.5 \\
\hline United Kingdom & 120.8 & 76.5 & 197.3 & 134.7 \\
\hline United States & $1,107.4$ & 326.5 & $1,433.8$ & $9,01.3$ \\
\hline Total DAC countries & $1,702.9$ & $1,031.6$ & $2,734.5$ & $1,338.5$ \\
\hline $\mathrm{EC}$ & 67.4 & 29.9 & 95.7 & 10.8 \\
\hline Total DAC members & $1,770.3$ & $1,031.5$ & $2,801.8$ & $1,349.4$ \\
\hline
\end{tabular}

The Center for Global Development has analyzed the policies and practices of PEPFAR, the Global Fund and the World Bank's MAP in Mozambique, Uganda and Zambia, and compared these systems against six key funding practices that can help donors support the national AIDS response in a manner consistent with the aid effectiveness principles of the Paris Declaration. These best practices are: 
working with the government; building local capacity; keeping funding flexible; selecting appropriate recipients; making the money move; and collecting and sharing data. This study made the following recommendations to all three donors to increase the effectiveness of aid: (1) Jointly coordinate and plan activities to support the National AIDS Plan; (2) Assist the host government in tracking total national AIDS funds; (3) focus on building and measuring capacity; (4) develop strategies with host governments and other donors to ensure financial sustainability; and (5) strengthen financial data collection and disclosure. The study also offered specific recommendations for how each donor can improve its own program to increase the effectiveness of aid (Oomman et al., 2007). These specific recommendations are addressed further below.

\subsection{The World Bank: A Development Institution}

Since its foundation since the end of the World War II, the World Bank has grown in size and importance. In 2008, it provides financial and technical assistance to developing countries through two development institutions owned by 185 member countries - the International Bank for Reconstruction and Development (IBRD) and the International Development Association (IDA). The World Bank's current mission is to reduce global poverty and to improve living standards. The IBRD focuses on middle income and creditworthy poor countries, while IDA focuses on the poorest countries. Together they provide low-interest loans, interest-free credit and grants to developing countries for education, health, infrastructure, communications and other development programs. The World Bank's traditional loan package integrates loans with analytic and advisory services. The World Bank's research program supports studies on a range of development issues (http://web. worldbank.org).

\subsubsection{Nature of World Bank Operations Related to HIV/AIDS}

The World Bank provides loans to national governments to assist in the implementation of national HIV/AIDS programs. The Bank also does research and provides assistance to make national AIDS programs more effective. The World Bank's first HIV/AIDS-related project was in 1988. Between 1988 and 2005, the Bank loaned over USD 2.5 billion to finance national HIV/AIDS programs.

The World Bank organizes its AIDS-related activities globally, through its "Global HIV/AIDS Program of Action" and six regional HIV/AIDS programs: (1) Sub-Saharan Africa, (2) East Asia and the Pacific, (3) Europe and Central Asia, (4) Latin America and the Caribbean, (5) Middle East and North Africa, and (6) South Asia. The purpose of this organizational structure is to have a global focus 
that takes regional differences into account and to define the World Bank's role in relation to other multilateral and international actors. The overall goals of these programs are prevention and treatment, taking into account local transmission patterns and sources of infection, in order to avoid a mismatch between funding and infection patterns in national programs (World Bank 2005a).

The World Bank's programs seek to focus support where national programs need it the most. The World Bank has adopted the "Three Ones principles", noted above. The World Bank monitors and evaluates its programs to ensure HIV/AIDS programs are context-specific. The World Bank also seeks to integrate HIV/AIDS issues into the broader development planning process. The World Bank recognizes the need to make all of the key players part of each national strategy - governments, the private sector, community and civil society organizations, people living with HIV/AIDS, NGOs and international organizations (World Bank 2005a).

The Bank's Program of Action focuses on five areas: (1) Sustained funding for HIV/AIDS programs and health systems; (2) Better national HIV/AIDS planning, focused on high-risk groups and locations; (3) Accelerating implementation of national HIV/AIDS plans by overcoming administrative constraints that delay the use of new funding; (4) Building country monitoring and evaluation systems and capacity to collect, analyze and use data; and (5) Improving and applying knowledge through impact evaluations and analysis (World Bank 2005a).

\subsubsection{The Need for Sustained Funding}

Sustained funding is crucial. Once people with HIV begin taking medication, they need a reliable supply of medication and their response to the medication needs to be monitored on an ongoing basis. If the underlying funding is not sustained, and medication and laboratory work get suspended, individuals with HIV will become more infectious and develop drug-resistant viruses. Thus, the suspension of treatment is not only inhumane, but also makes prevention and treatment more difficult.

\subsubsection{Focus on High-Risk Groups and Locations}

The need to focus on high-risk groups and locations flows from the fact that resources are limited and need to be used effectively. Targeting tripartite preventiontreatment-human rights strategies at high-risk groups has proved effective in countries like Brazil (see Chap. 2). Targeting high-risk groups is a key component of an effective national HIV/AIDS strategy, particularly when those groups have been marginalized through discrimination.

Figure 7.6 shows the mismatch between most affected groups and funding in Ghana. It is important to note that the transmission patterns for HIV/AIDS in Ghana are not representative. However, the mismatch between the most affected groups and the allocation of funding in Ghana highlights the importance of matching funding to prevailing prevalence and transmission patterns in a given country or region. 


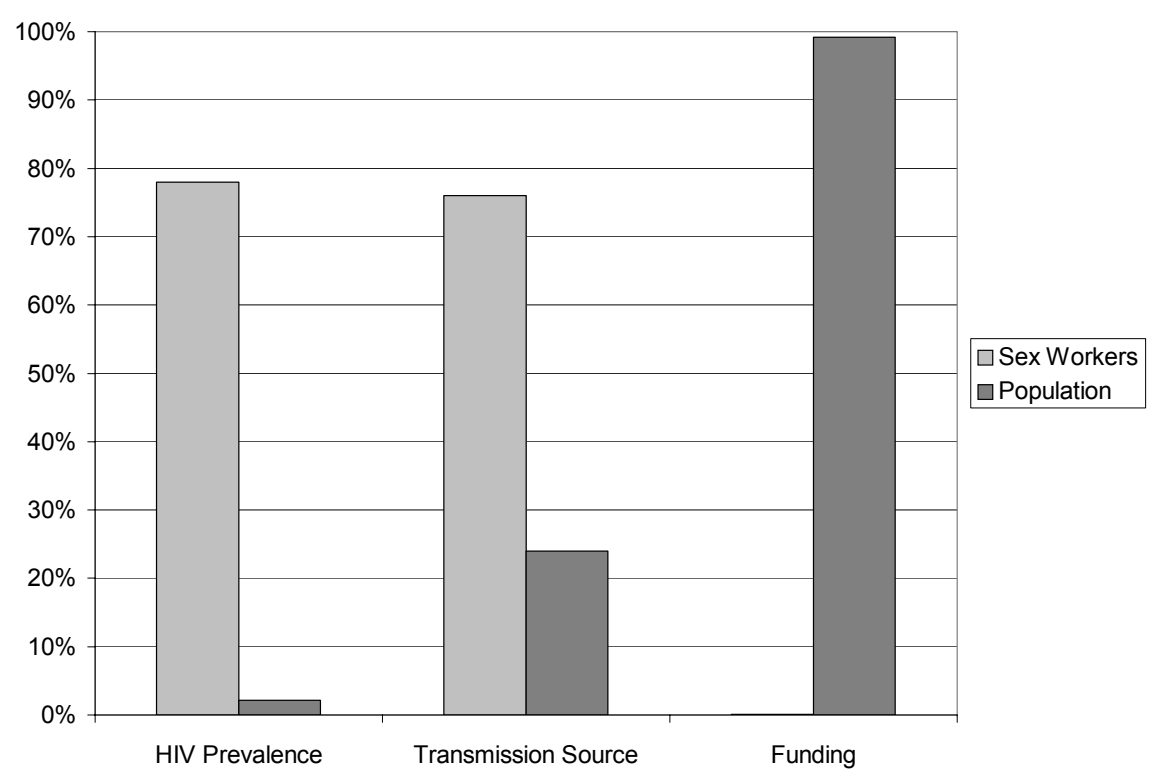

Fig. 7.6 Mismatch between funding and affected groups in Ghana. Source: Wilson (2007)

\subsubsection{Accelerated Implementation of Funding}

While funding for HIV/AIDS programs has increased, there remains an "implementation gap" between the available funding and its deployment. This is due to impediments to quick implementation: a lack of skilled personnel; unpredictable or conditional funding; burdensome disbursement and procurement processes; government reluctance to contract out implementation to civil society or the private sector; and multiple systems of management, monitoring and evaluation to meet different donor requirements. To address this problem, the World Bank is simplifying its own processes and procedures, strengthening its Implementation Advisory Service and coordinating UN, Global Fund and World Bank actions through the Global Joint Problem-Solving and Implementation Support Team (GIST) (World Bank 2005a).

\subsubsection{Country Monitoring and Evaluation Systems and Data Capacity}

The Global AIDS Monitoring and Evaluation Support Team (GAMET) seeks to build a well-functioning monitoring and evaluation system in each country, to enhance the impact of national programs. GAMET provides field support to build country systems and capacity, as well as training and guidelines (World Bank 2005a). 


\subsubsection{Impact Evaluation and Analysis to Improve Program Impact}

The World Bank's main focus has shifted from getting resources to countries to ensuring that more impact evaluations are done of Bank-supported HIV/AIDS programs, including prospective evaluations that are begun ahead of project implementation. The regional and country strategies include plans for analytical work, to be complemented by analysis of cross-cutting and cross-country issues to highlight good practices (World Bank 2005a).

Most HIV Monitoring and Evaluation (M\&E) systems - the 3rd of the Three Ones - are not fully functional. For example, in 2006 the M\&E plans in 13 countries out of 20 in East and Southern Africa had yet to be implemented (Kasheeka et al., 2006).

\subsubsection{Scope of World Bank Operations}

The scope of the World Bank's operations is quite wide, covering a wide range of development issues in a large number of countries, in addition to its work related to HIV/AIDS. Table 7.10 shows the distribution of World Bank lending by theme and sector from 2001 to 2006. Figure 7.7 shows the distribution of World Bank lending by region.

Table 7.10 World bank lending by theme and sector in millions of dollars

\begin{tabular}{lrrrrrr}
\hline Theme & 2001 & 2002 & 2003 & 2004 & 2005 & 2006 \\
\hline $\begin{array}{l}\text { Economic management } \\
\text { Environmental and natural resource }\end{array}$ & 1,354 & 1,408 & 777 & 428 & 594 & 213 \\
management & 924 & 1,102 & 1,304 & 2,493 & 1,387 \\
$\begin{array}{l}\text { Financial and private sector } \\
\text { development }\end{array}$ & 3,940 & 5,055 & 2,882 & 4,176 & 3,862 & 6,137 \\
$\begin{array}{l}\text { Human development } \\
\text { Public sector governance }\end{array}$ & 1,134 & 1,756 & 3,374 & 3,079 & 2,951 & 2,600 \\
Rule of law & 2,053 & 4,247 & 2,464 & 3,373 & 2,636 & 3,820 \\
$\begin{array}{l}\text { Rural development } \\
\text { Social development, gender, and }\end{array}$ & 410 & 273 & 530 & 503 & 303 & 757 \\
inclusion & 1,822 & 1,600 & 1,910 & 1,507 & 2,802 & 2,215 \\
Social protection and risk & 1,469 & 1,385 & 1,003 & 1,557 & 1,285 & 1,094 \\
management & 1,651 & 1,086 & 2,324 & 1,577 & 2,437 & 1,891 \\
$\begin{array}{l}\text { Trade and integration } \\
\text { Urban development }\end{array}$ & 1,059 & 300 & 566 & 1,212 & 1,079 & 1,610 \\
Total & 1,458 & 1,482 & 1,576 & 1,358 & 1,860 & 1,911 \\
\hline & 17,250 & 19,519 & 18,513 & 20,079 & 22,307 & 23,641 \\
\hline
\end{tabular}


As of 24 June 2004, the World Bank had 72 approved and active HIV/AIDS projects with an HIV/AIDS component of more than USD one million, in 60 countries. These projects include health sector support and reform, prevention and control programs, human resources development and education and national AIDS programsupport. (http://siteresources.worldbank.org / INTHIVAIDS / Projects/20385466/ Financing06-24-04.xls) Some of these projects are conducted as part of the World Bank's regional initiatives. For example, the World Bank's Africa MAP was designed to help countries intensify and expand their multi-sector national responses to the HIV epidemic, to dramatically increase access to HIV prevention, care, and treatment (World Bank 2007). Below, we look at the example of Rwanda's MAP project.

\section{Total IBRD-IDA Lending by Region}

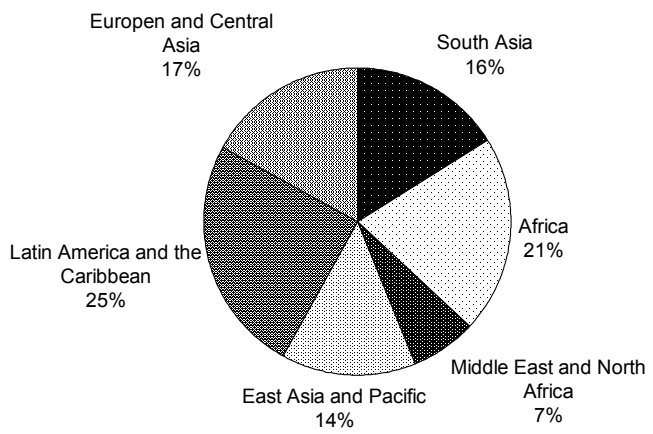

Fig. 7.7 Proportion of total lending of the World bank by region. Source: World Bank, 2006 Annual Report

\subsubsection{The Africa Multi-Country HIV/AIDS Program (MAP) in Rwanda}

In Rwanda the World Bank used MAP community grants for HIV Initiatives to fund over 100 civil society organizations to provide preventive, medical and support services for people living with HIV. In 2002, Rwanda was among the ten countries most severely affected by HIV and had recently emerged from a genocide/war. The USD 30.5 million grant became effective on 11 August, 2003 and was fully committed and almost fully disbursed by the end of 2006 . The World Bank Board of Directors approved additional financing of USD 10 million on 2 February 2007 to consolidate gains from the initial investments and plan for their sustainability.

As Table 7.11 shows, about 30\% of the World Bank's funds went to poverty mitigation combined with HIV prevention messages. Roughly $17 \%$ paid for prevention activities, such as social mobilization, advocacy, condom promotion and HIV testing. About $19 \%$ of the funds were used for institutional support, capacity building, and monitoring and evaluation of programs. Just over $10 \%$ paid for HIV/ AIDS treatment and care. The costs of administering this project were roughly $6 \%$ of the total grant over the life of the project (World Bank 2007). 
Table 7.11 Rwanda HIV/AIDS multi-sectoral project, distribution of world bank funds (in millions of USD)

\begin{tabular}{lrc}
\hline Activity & Funds & Percent (\%) \\
\hline HIV/AIDS treatment and care & 3.1 & 10 \\
General health systems support & 3.1 & 10 \\
Home based care & 2.1 & 7 \\
HIV/STI prevention & 5 & 17 \\
Mitigation & 8.8 & 30 \\
Multi-sectoral capacity building & 5.6 & 19 \\
Project management & 1.9 & 6 \\
\hline \multicolumn{2}{c}{ Source: World Bank 2007 }
\end{tabular}

\section{Female Sex Workers in Rwanda}

One part of this project was to help female sex workers to find different sources of income. Several factors contributed to the success of this project. First, the project engaged local champions to mobilize people (in this case, the deputy mayor in charge of social welfare on the district HIV/AIDS commission became personally engaged in designing the program design). Second, to break the AIDS-poverty cycle, poverty mitigation accompanied preventive measures (in this case, new sources of income provided a basis for further, community-based economic development projects). Third, the project sought to empower women to benefit the whole family (in this case, empowering them to provide better education and health care for their children). Fourth, ongoing support was provided to sustain the success of the project (in this case, to prevent the women returning to prostitution when challenges arise) (World Bank 2007). However, as we will see in Chap. 9, programs for sex workers that focus on alternative employment have been criticized for contributing to their stigmatization and failing to address the needs of those who continue to earn their income from sex work.

\section{Orphans and Vulnerable Children in Rwanda}

Another part of the Rwanda MAP project provided orphans and vulnerable children with sewing machines and training as tailors so that they could start a clothes-manufacturing association. This program combined information about HIV and AIDS, reproductive health and life skills with income generating activities. The children then served as role models and sources of information on HIV and AIDS for other vulnerable children. The experience with this program suggests three key factors for success. First, establish solidarity among participants, in this case by bringing the children together to find solutions to their problems and design their own interventions. Second, enable beneficiaries to be role models for behavioral change. Third, address poverty and vulnerability in order to make AIDS prevention effective (World Bank 2007). 


\section{HIV Awareness and Testing for Youth in Rwanda}

In yet another part of the MAP project, the Rwanda National Youth Council (CNJR) created a voucher system for expanding access to HIV testing for youths aged 10-24 (almost $40 \%$ of the population). The rationale behind promoting testing is that enabling people to learn their HIV status is a first critical step in changing behavior. The CNJR trained 230 peer educators in behavioral change communication and reached out to youth through anti-AIDS clubs and sports and cultural activities. The voucher system enabled youths to go to local health facilities on designated days, minimizing waiting times. The MAP funding was used to pay for these services. This approach was more cost-effective (USD 2 per person) than using mobile units to reach these youths (USD 10 per person). It also enhanced the returns on Global Fund investments in facility-based services. In the first 4 months almost 70,000 youths were tested. About $6 \%$ tested HIV positive. The three main lessons from the CNJR campaign were (1) HIV testing is critical to modifying sexual behavior and expanding condom use; (2) better knowledge leads to greater empathy and solidarity with people living with HIV; and (3) awareness campaigns foster a culture of responsibility, trust and faithfulness among young couples (World Bank 2007).

\section{Expanding Access to Anti-Retroviral Treatment in Rwanda}

The Rwandan government developed a treatment plan with the support of the Clinton Foundation. A user fee policy with a sliding scale results in most Rwandans receiving free care because they live below the poverty line. The Rwandan government, the World Bank, the Clinton Foundation, the Global Fund, US Centers for Disease Control and Prevention (CDC) and the US Government/PEPFAR worked together to design, implement and monitor the treatment program. Different sites were funded by different donors (the World Bank, the Global Fund and the US Government/PEPFAR). Patients receiving treatment increased from 870 patients at seven sites at the end of 2002 to roughly 32,000 patients at 130 sites nationwide in the first half of 2007 (over 50\% of those who need care). Using the national procurement system, the World Bank and the Global Fund finance generic drugs and the US Government/PEPFAR pays for brand name drugs. The Clinton Foundation has helped to lower the prices paid for drugs and diagnostics. PEPFAR funded the "TRACNet" system, which uses mobile phones to transmit information. It tracks the number of patients on treatment and the drugs dispensed nation-wide, to manage the treatment program and supplies efficiently and to avoid drug shortages that would lead to interruptions in treatment. Interruptions in treatment could diminish the effectiveness of treatment by creating resistance to the drugs being used and raise costs by requiring the use of other drugs and medical treatments. Performance-based contracting and bonuses for health care staff expanded key HIV services rapidly in a relatively short time (for example, the number of HIV tests performed by staff) (World Bank 2007). 


\subsubsection{Central America and the Need for Human Rights Protection}

The World Bank has also addressed the HIV/AIDS epidemic in Central America on a regional basis. Four of the six countries in Latin America with the highest HIV prevalence are in Central America. Two Central American countries have prevalence rates above $1 \%$, which is a key threshold for an HIV epidemic to run out of control unless prevention efforts are improved among high-risk groups, such as commercial sex workers, men who have sex with men and prisoners (see Chap. 2). The adult HIV prevalence rates are as follows (in alphabetical order): Costa Rica (0.6\%); El Salvador (0.6\%); Honduras (1.6\%); Guatemala (1\%); Nicaragua $(0.2 \%)$ and Panama $(0.9 \%)$. By 2010 , the adult HIV prevalence rate may reach $2 \%$ in the region. HIV transmission in Central America is primarily associated with heterosexual sex (with the exception of Costa Rica), as in Africa and the Caribbean (World Bank 2006). The World Bank has developed a model to help governments to allocate resources efficiently to prevent the maximum number of new infections (World Bank 2003). In Central America, the World Bank also studied the extent of discrimination and stigmatization and identified areas where changes in general legislation or HIV/AIDS laws are necessary (World Bank 2006).

\subsubsection{The Effectiveness of the World Bank}

Economist Jagdish Bhagwati has taken the World Bank to task for not having a sufficiently narrow focus. In particular, he has opined that the world does not need a global think tank staffed by 8,500 people and that the World Bank should not be involved in intellectual programs for countries, like India, that have sufficient resources to handle their own affairs. Thus, in his view, the World Bank should be cut to 300 staff to focus on a good intellectual program for countries that need it (BBC News 2007a).

Easterly (2006) has accused the World Bank of wasting resources on inefficient bureaucracies and for having a late response to the HIV/AIDS epidemic (it had only implemented one project by 1993 and only completed ten by 1998). In a comparative study of US and World Bank funding for HIV/AIDS between 1995 and 1999, Smith (2007) found that, although there is a positive correlation between the incidence of HIV/AIDS and poverty and the likelihood of receiving aid from the World Bank, the US government is more responsive to the incidence of HIV/AIDS and poverty with its foreign aid donations. Moreover, the World Bank allocates more money to countries with political systems that are less likely to use the funds for public goods like education, treatment and health care, and does not do as well as the United States in targeting aid to countries most in need of funding (Smith 2007). 
It is difficult to assess the success of the World Bank's HIV/AIDS programs, since they are ongoing, diverse and numerous. However, the World Bank's current programs have incorporated several features that suggest that they will be effective: following "the three ones", ongoing support, monitoring and evaluation of programs for effectiveness, sharing information regarding the factors that contribute to the success of individual projects and working with other multilateral and bilateral donors to reduce overlap.

The World Bank has undertaken or commissioned three reviews of its HIV/AIDS work (World Bank 2005a). The "Interim Review of the Multi-Country HIV/AIDS Program for Africa", was done in early 2004. This review listed the following key barriers and challenges: (1) Many national HIV/AIDS plans are not strategic, and are poorly prioritized; (2) Prevention, care and treatment efforts are too small, and coverage is too low; (3) Management and implementation constraints hamper action; (4) Health systems are weak and overwhelmed, particularly with efforts to expand access to treatment; (5) The effort to expand antiretroviral (ARV) treatment raises difficult issues of equity, sustainability and adherence; (6) Prevention remains inadequate, regardless of the stage of the epidemic in a given country; (7) Stigma and discrimination, denial and silence persist, to the point that some people would rather die than let others know they are HIV positive; and (8) Donors sometimes create additional problems for countries, for example in Tanzania, where program managers spend more time meeting the needs of visiting donors than implementing the programs.

The World Bank's Operations Evaluation Department (OED) has assessed the development effectiveness of the World Bank's country-level HIV/AIDS assistance (defined as policy dialogue, analytical work and lending to reduce the scope or impact of the AIDS epidemic) (World Bank 2005b). The OED's assessment found that the World Bank's assistance has induced governments to act earlier or in a more focused and cost-effective way. It has helped raise political commitment, create or strengthen AIDS institutions, enlist NGOs, and prioritize activities. The OED's assessment also found that political commitment and capacity had been overestimated and needs continuous assessment. Moreover, failure to reach people with the highest risk behaviors likely had reduced the efficiency and impact of assistance. The effectiveness of the national response had been hampered by weak monitoring and evaluation and the failure to ensure that country-based research is focused on priorities areas.

As a result of its assessment, the OED made several recommendations for the future work of the World Bank in the HIV/AIDS epidemic. First, it should help governments use human and financial resources more efficiently and effectively. Second, the World Bank should help governments to be more strategic and selective, and to prioritize activities that will have the greatest impact. Third, it should work to strengthen national institutions for managing and implementing the long-run response, particularly in the health sector. Fourth, it needs to improve the local evidence base for decision-making and create incentives to ensure that program decisions are guided by relevant local evidence and rigorous analytical work. 
Wilson has concluded that the World Bank's MAP programs must place far greater emphasis on improved surveillance, research and analysis in order to design more intelligent MAPs that take into account prevalence and transmission patterns, the distinction between generalized and concentrated epidemics, the effect of stigma and community values on treatment programs and the role of political leadership in national AIDS strategies. The money must follow the epidemic by focusing primarily on normative and behavioral change in the general population in generalized epidemics and on high coverage of vulnerable groups in concentrated epidemics. In generalized epidemics, emphasis must shift from knowledge and awareness to normative change. In more concentrated epidemics, the World Bank needs greater focus on groups and areas where transmission is occurring (Wilson 2007).

A 2007 survey revealed that more than a third of patients on HIV medication in sub-Saharan Africa die or discontinue their treatment within 2 years of starting; only $61.6 \%$ of all patients were still receiving medication. The study found that many were too late taking up ARV drugs and died within a few months of commencing treatment. For some it was impractical to travel to distant clinics. The researchers also found evidence that, in cases where patients had to pay for ARVs, some stopped treatment. Some people also suffered from stigma: in some workplaces, people are not able to carry their ARVs and take their ARVs freely at workplaces. Retention rates between individual ARV programs varied widely across Africa. One program in South Africa retained as many as $85 \%$ of their patients after 2 years while another in Uganda retained only $46 \%$ of patients after the same period of time (BBC News 2007b).

The World Bank was a member of the GTT. The agreements reached by the GTT, including the division of labor, are reflected in the World Bank's Program of Action (World Bank 2005a). However, as noted above, more work is needed to resolve the problems created by the proliferation of donors.

In its 2007 study of funding practices, the Center for Global Development made the following recommendations to the World Bank regarding MAP: (1) focus resources on building government capacity; (2) become a knowledge bank, with a focus on prevention; (3) make the transition to the use of existing government systems; (4) increase individual disbursement amounts; and (5) publicly disclose data (Oomman et al., 2007).

\subsection{The International Monetary Fund (IMF): A Multilateral Financial Institution}

Dominique StraussKahn, who became the director general of the IMF on 1 November 2007, has noted the need for the IMF to adapt to a new global economic order (to better reflect the rise of emerging market economies and the interests of less developed ones, plus the need to better regulate globalization) and to downsize or die. In StraussKahn's view, the IMF needs to reach out to other multilateral organizations, in particular the World Bank. The IMF also needs to mend fences in a meaningful way with regions of the world that felt hard done by during 
past crises. In this regard, he said, My first priority is to cross (Washington DC's) 19th street and go to the other side where there's the World Bank. My second priority is to cross the equator to Latin America and my third priority is to cross the Pacific to Asia.'Clearly this means he does not believe there is enough communication between the IMF and the World Bank, despite the physical proximity of their offices. This drives home the need for more coordination among international institutions (Love and Pattanaik, 2007).

\subsubsection{Nature of IMF Operations}

The IMF is an international organization that was established to promote international monetary cooperation, exchange stability and orderly exchange arrangements; to foster economic growth and high levels of employment; and to provide temporary financial assistance to countries to help ease balance of payments adjustment. It has 185 member countries.

The IMF is to be guided in all its policies and decisions by the purposes set forth in Article I of the Articles of Agreement of the International Monetary Fund. Article I sets out these purposes as follows:

1. To promote international monetary cooperation through a permanent institution which provides the machinery for consultation and collaboration on international monetary problems.

2. To facilitate the expansion and balanced growth of international trade, and to contribute thereby to the promotion and maintenance of high levels of employment and real income and to the development of the productive resources of all members as primary objectives of economic policy.

3 . To promote exchange stability, to maintain orderly exchange arrangements among members, and to avoid competitive exchange depreciation.

4. To assist in the establishment of a multilateral system of payments in respect of current transactions between members and in the elimination of foreign exchange restrictions which hamper the growth of world trade.

5. To give confidence to members by making the general resources of the Fund temporarily available to them under adequate safeguards, thus providing them with opportunity to correct maladjustments in their balance of payments without resorting to measures destructive of national or international prosperity.

6. In accordance with the above, to shorten the duration and lessen the degree of disequilibrium in the international balances of payments of members.

Since inception the IMF's purposes have remained the same, but its operations have developed over time, particularly with respect to surveillance of public expenditure management systems, financial assistance and technical assistance. 


\subsubsection{Scope of IMF Operations}

The IMF focuses on three kinds of operations. First, surveillance operations monitor economic and financial developments and provide policy advice, aimed especially at crisis prevention. Second, the IMF also lends to countries with balance of payments difficulties, to provide temporary financing and to support policies aimed at correcting the underlying problems. Loans to lowincome countries are also aimed at poverty reduction. Third, the IMF provides countries with technical assistance and training. The IMF also conducts economic research and gathers statistics related to these three types of operations. An IMF loan usually stipulates the specific policies and measures a country has to implement to resolve its balance of payments problem. Lowincome countries may borrow at a concessional interest rate through the Poverty Reduction and Growth Facility and the Exogenous Shocks Facility. Noneoncessional loans are subject to the IMFs marketrelated interest rate, which is revised weekly to take account of changes in shortterm interest rates in major international money markets. Large loans carry a surcharge. The IMF also provides emergency assistance to support recovery from natural disasters and conflicts, in some cases at concessional interest rates (http://www.imf.org).

The IMF can allocate additional spending to HIV/AIDS as part of national povertyfeduction strategies. The IMF also provides advice to countries on the macroeconomic impact of HIV/AIDS and how to manage inflows of foreign aid. Countryłevel HIV prevention and treatment programs form part of many Poverty Reduction Strategy Papers, which provide the operational basis for IMF and World Bank loans to lowincome countries and fo $r$ debt relief under the Heavily Indebted Poor Countries (HIPC) Initiative (IMF 2005).

Unlike development banks, the IMF does not lend for specific projects. Thus, unlike the World Bank and the Global Fund, the IMF does not have projects specifically aimed at HIV/AIDS. Rather, HIV/AIDS issues are addressed as part of the IMF's general operations. The research of the IMF on HIV/AIDS has been focused primarily on its macroeconomic impact.

\subsubsection{Effectiveness of the IMF}

With respect to HIV/AIDS, IMF (and World Bank) policies have been criticized for not considering the impact of structural adjustment requirements (austerity measures) on the spread of HIV/AIDS. The IMF has also been criticized for making debt repayment a higher priority than health care, thereby undermining the ability of national governments to finance health care.

Peter Lurie et al. (1995) argued that exporteriented, structuraladjustment policies were undermining HIV/AIDS control by contributing to social changes that favor the spread of HIV in the developing world, through increased mobility, migration, urbanization and dislocation of family units. 
Hanlon (1999) noted that the IMF required the Mozambican Government and other African governments to reduce spending in the 1990s without decreasing repayments of its debts, thereby contributing to cuts in spending on health services that increased corruption in hospitals. The international community later recognized that much of Africa's debt could not be paid and agreed to cancel some debts. This led to the HIPC Initiative in 1996. However, Hanlon reported that with the HIPC Mozambique would still be paying back USD 100 million a year, because the World Bank and IMF agreed to cancel only the part of the debt that Mozambique was not paying. The HIPC only canceled the uncollectable debt. Thus, Mozambique was paying USD 275,000 per day in debt service, but only USD 100,000 per day for its entire health service.

In 2003, African Ministers of Finance, Planning and Economic Development warned that the enhanced HIPC Initiative was not delivering long-term debt sustainability. They recommended that the IMF impose fewer structural conditions and provide for outcomes-based conditions where appropriate. The Ministers also urged the IMF and World Bank, bilateral partners and the African Development Bank to avoid "cross-conditionalities" that impede access to resources. They recommended that to provide greater fiscal flexibility, the IMF should also analyze the linkages, trade-offs and policy choices required to attain the Millennium Development Goals (which include addressing the HIV/AIDS pandemic). They also proposed that evaluating exogenous shocks should be a standard feature of IMF discussions with member states, and that access to loans should be extended to countries suffering from exceptional exogenous shocks such as the onslaught of new communicable diseases. On HIV/AIDS specifically, the Ministers urged the IMF and World Bank to consider revising the eligibility criteria for assistance to middle-income countries affected by the AIDS epidemic, and to find ways of ensuring that countries could expand expenditure on health and social welfare without violating conditions that impose limits on public spending (ECA 2003).

The IMF restricted aid to Mozambique's budget in order to control inflation and required donors' aid to fund more projects outside the state budget, contrary to the policy of many donors (Hanlon 2006). The IMF Resident Representative Mozambique argued that it was difficult for the government to be certain about the level of donor payments in the medium term, and it might not be prudent to make medium term expenditure commitments (such as the hiring of health personnel) given the uncertainty about whether the money would still be available over the next budget cycle.

The IMF Representative recognized the need to improve the design of the IMF fiscal target taking into account that donor aid has increasingly moved away from lending to support capital investment projects, and toward direct budget support for hiring personnel and purchasing medicine (Perone 2006). This story highlights the ongoing importance of policy coordination on the ground between the IMF, donors and national governments and the need for sustainable funding from donors. 


\subsection{The Global Fund: A Fundraising and Financing Institution}

The Global Fund was created to raise and disburse additional private and public sector funds for the fight against AIDS, tuberculosis and malaria. As of October 2007, the Global Fund had committed USD 8.4 billion in 136 countries. It provides around two thirds of all international financing for tuberculosis and malaria and close to a quarter of the global resources for AIDS. As we saw in Chap. 4, malaria prevention is a cost-effective means to prevent HIV/AIDS in areas with high malaria prevalence, because of the impact of life-expectancy on incentives to change sexual behavior to reduce the risk of HIV/AIDS. The prevalence of HIV/AIDS also has a direct impact on the spread of extensively drug-resistant tuberculosis (XDR-TB). People living with AIDS are especially susceptible to XDR-TB because of their depressed immune systems, increasing the risk that XDR-TB will spread rapidly in sub-Saharan Africa (Picard 2007). In turn, an XDR-TB epidemic could reduce life expectancy, thereby hampering HIV/AIDS prevention. Thus, it is important to attack all three diseases together.

There are two key differences between the Global Fund and the World Bank. First, the Global Fund is a hands-off operation that focuses on financing rather than implementation, whereas the World Bank is very involved in the implementation of its programs. Second, the Global Fund has a much narrower scope of operations with respect to the issues that it tackles, being restricted to AIDS, tuberculosis and malaria. The World Bank has a much broader development agenda, albeit one that incorporates health care in general, and HIV/AIDS in particular, into its development programs.

\subsubsection{Nature of Global Fund Operations}

Section II of the Framework Document of the Global Fund sets out its purpose in the following terms:

The purpose of the Fund is to attract, manage and disburse additional resources through a new public-private partnership that will make a sustainable and significant contribution to the reduction of infections, illness and death, thereby mitigating the impact caused by HIV/AIDS, tuberculosis and malaria in countries in need, and contributing to poverty reduction as part of the Millennium Development Goals (Global Fund 2003).

Section II of the Framework Document clarifies that the Fund's mandate is to finance prevention, treatment, care and support in an integrated and balanced way, not to implement such programs. The Framework Document provides further that the Global Fund "should make use of existing international mechanisms and health plans". In making its funding decisions, the Global fund is to focus on best 
practices and performance, linking resources to the achievement of clear, measurable and sustainable results. Another focus is on the creation, development and expansion of government/private/NGO partnerships. The Global Fund is required to support programs that reflect "national ownership", by focusing upon the technical quality of proposals, while leaving the design of programs and priorities to partners within recipient countries.

"Country Coordinating Mechanisms" (CCMs) are country-level partnerships that develop and submit grant proposals to the Global Fund based on priority needs at the national level. After grant approval, they oversee progress during implementation. CCMs include representatives from the public and private sectors, including governments, multilateral or bilateral agencies, non-governmental organizations, academic institutions, private businesses and people living with the diseases.

The proposals that are supported by the Global Fund must be consistent with international law and agreements, respecting intellectual property rights laws, such as TRIPS. At the same time, the programs should encourage efforts to make quality drugs and products available at the lowest possible prices and give priority to the most affected countries and communities, and to those countries most at risk. The Framework Document provides specifically for programs that aim to eliminate the stigmatization of and discrimination against those infected and affected by HIV/AIDS, especially for women, children and vulnerable groups.

The Framework Document requires the Global Fund to use, wherever possible, existing monitoring and evaluation mechanisms. Monitoring at the country level is country-driven, but also linked to the Fund's monitoring and evaluation system at a global level. Grantees need to be: (1) accountable to donors for the use of funds and achievement of results; (2) responsive to developing countries; and (3) responsive to the needs of those infected and directly affected by the three diseases. The Framework Document contemplates the following options for who oversees the process of monitoring both global and local program progress on behalf of the Global Fund Board: Global Fund Secretariat; Ad hoc monitoring and evaluation working group; the World Bank's Operations Evaluation Department; a UN agency; existing mechanisms (UNAIDS, Stop TB, Roll Back Malaria); an independent monitoring and evaluation oversight committee appointed by the Global Fund Board; or a third party (for example, an accounting firm or university).

The World Bank serves as the Trustee for the Global Fund. The Trustee has primary responsibility for financial accountability, including: (1) collection, investment, and management of funds; (2) disbursement of funds to national-level entities, on the instruction of the Global Fund Board; (3) reporting to stakeholders on the financial management of the Fund and the allocation of Fund resources; and (4) independent audits.

Local Funding Agents are organizations (mainly multinational audit firms) that the Global Fund contracts to provide the Secretariat with the information used to 
make decisions regarding grant management. KPMG and PriceWaterhouseCoopers act as Local Funding Agents in $80 \%$ of the 136 countries involved and are responsible for $83 \%$ of approved funds. Local Funding Agents verify, assess and report on the capacity of the agencies that implement funded programs and on program results and make recommendations regarding future funding. The outsourcing of fiduciary risk management to Local Funding Agents obviates the need for Global Fund offices in the relevant countries, thereby enabling the Global Fund to have a leaner administration and to set up more rapidly in a country (Euro Health Group 2007).

\subsubsection{Scope of Global Fund Operations}

The Framework Document requires the highest priority to be given to proposals from countries and regions with the greatest need, based on the highest burden of disease and the least financial resources. These are identified as including subSaharan Africa, currently the region most affected, as well as some countries within the Caribbean, Asia-Pacific, Latin America and Central and Eastern Europe. The criteria for identifying these proposals include: (1) disease burden for HIV, TB and/or malaria; (2) poverty indicators, such as per capita GNP and the UN Human Development Index; (3) potential for rapid increase in disease, based on indicators such as recent disease trends, size of population at risk, prevalence of risk factors, extent of cross-border and internal migration, conflict, or natural disaster; (4) political commitment, as indicated by contribution to the financing of the proposal, public spending on health, existence of supportive national policies or the presence of a national counterpart in the proposal; (5) existence of a country coordination mechanism, which consists of an inclusive collaborative partnership, with all relevant partners engaged in planning, decision-making and implementation. Figures 7.8 and 7.9 show the Global Fund's distribution of funds, by disease and by country income level. Figure 7.10 shows the Global Fund's expenditure targets for products and services. Figures 7.11 and 7.12 show the Global Fund's distribution of funds, by region and by sector of recipients.

The Framework Document requires the Global Fund to provide grants to public, private and non-governmental programs for the prevention, treatment, care and support of the infected and directly affected, which may include: increased access to health services; provision of critical health products (for example, bed nets; condoms; antiretroviral, anti-TB and anti-malarial drugs; treatment for sexually transmitted infections; laboratory supplies and materials; and diagnostic kits); training of personnel and community health workers; behavioral change and outreach; and community-based programs, including care for the sick and orphans.

Technical Review Panels, made up of independent, impartial teams of experts appointed by the Global Fund Board, review grant proposals, based on criteria set by the Board, and make recommendations to the Board for final decision. 


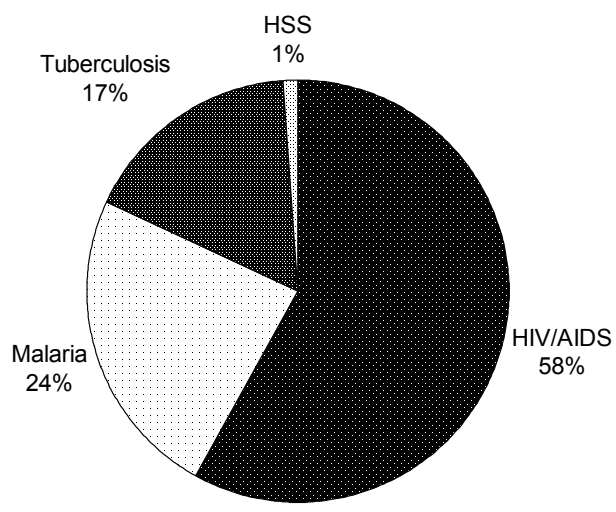

Fig. 7.8 Global fund's distribution of funds by disease (2001-2006). Source: Global Fund

\section{Distribution by Country Income}

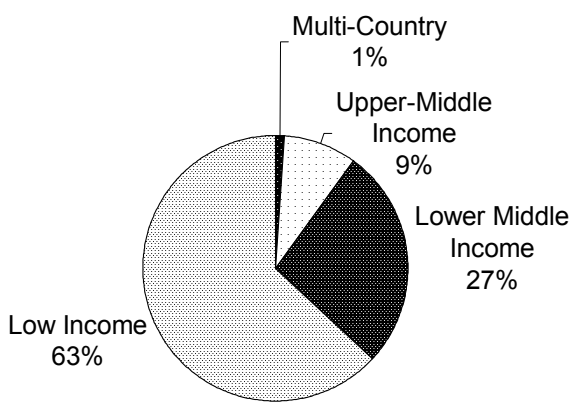

Fig. 7.9 Funding by Country Income Levels (2001-2006). Source: Global Fund

\subsubsection{Effectiveness of the Global Fund}

The Global Fund's Technical Evaluation Reference Group (an independent advisory body) was charged with overseeing a Five-Year Evaluation on the operations of the Global Fund, during 2006-2008. The first area of evaluation is "organizational efficiency", which analyzes whether the Global Fund is efficient and effective in fulfilling its core principles, including acting as a financial instrument rather than implementation agency and furthering country ownership. The second area of evaluation is "partnership environment", which considers how effective 


\section{Expenditure Target}

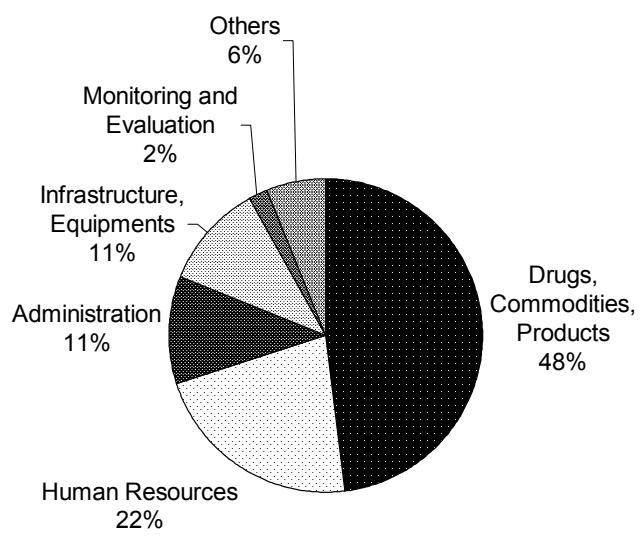

Fig. 7.10 Global fund expenditure targets for products and services. Source: Global Fund

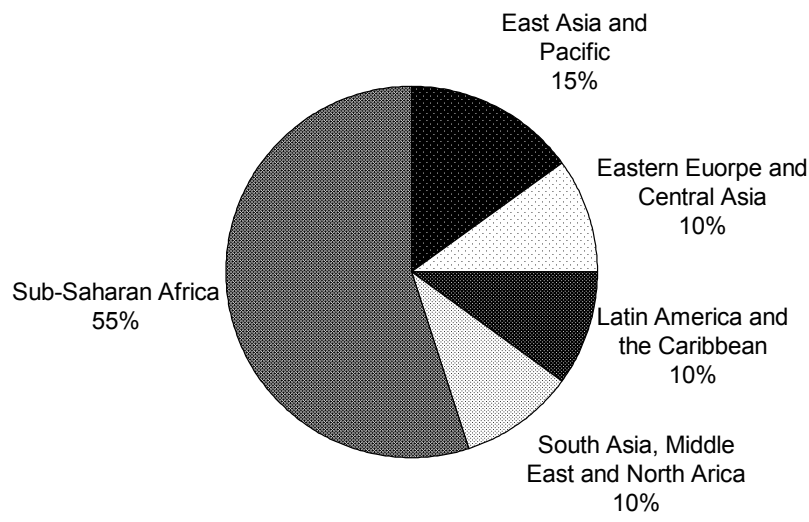

Fig. 7.11 Global fund expenditure by region. Source: Global Fund 


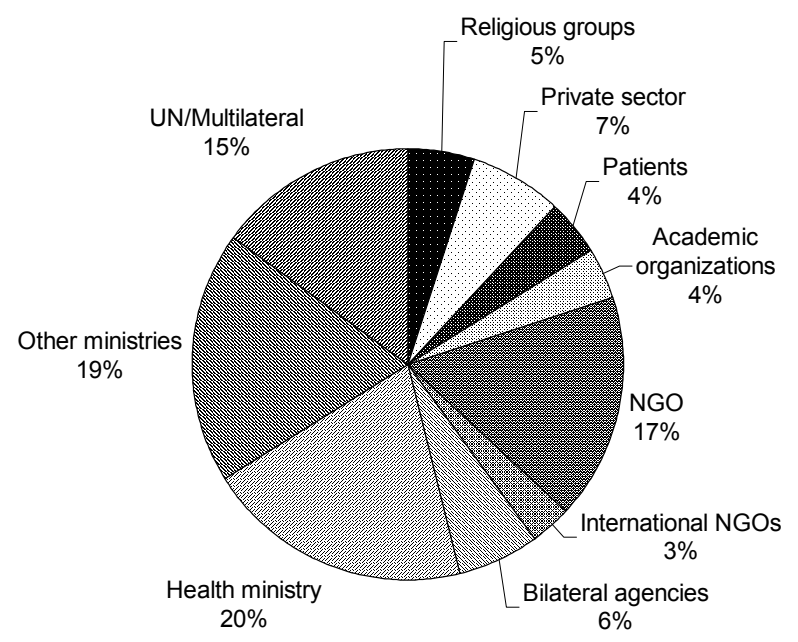

Source: The Global Fund to Fi_ht AIDS, Tuberculosis and Malaria

Fig. 7.12 Global fund, sector of recipients (2001-2006). Source: Global Fund

and efficient the Global Fund partnership system is in supporting HIV, malaria and TB programs at the global and country level. The third area of evaluation is "health impact", which studies the Global Fund's contribution to reducing the burden of the three diseases.

A striking feature of the Global Fund's very user-friendly web site is the Global Fund Evaluation Library (http://www.theglobalfund.org/en/links_resources/ brary/). This web page makes both internal and external evaluations of the Global Fund readily available and has the stated aim of improving the Global Fund's delivery of key services for HIV/AIDS, tuberculosis and malaria by stimulating open debate and evaluation of the Fund. This novel method of inviting and inciting critical evaluations, in order to improve performance, stands in contrast to the World Bank and IMF approaches to external criticism.

The Global Fund has been criticized for funding drugs without strengthening the underlying health systems. In response, the Global Fund opened the possibility of funding health system improvements, but this was not used often and rarely covered staff remuneration. The World Bank has proposed leaving the strengthening of health systems up to the World Bank, in order to avoid overlap. However, the World Bank itself has been criticized for poor performance in supporting and reinforcing public health services, particularly given its role, together with the International Monetary Fund, in maintaining limits on public health expenditures and wages. The Global Fund, with its narrow funding mandate, has also been criticized for not placing more conditions on the use of the resources provided and for giving into technical advisors from the World Bank and bilateral donors who oppose the exceptional nature of AIDS (Philips 2007). 
The Global Fund evaluates program performance after 2 years. The Center for Global Development analyzed data on 134 of the first 140 Global Fund grants evaluated in 2006. Due to the subjective nature of the evaluation process, this analysis should be seen as an analysis of evaluation scores rather than of the actual performance of the programs. Moreover, the results were not intended to be used to influence the distribution of funding, but rather to allocate resources for oversight and risk management. The programs that scored lowest had government agencies as principal recipients, had a large amount of funding, were focused on malaria, had weak initial proposals or were evaluated by the accounting firm KPMG. Countries with a high number of doctors per head, high measles immunization rates, few health-sector donors and high disease-prevalence rates had higher evaluation scores. Poor countries, those with small government budget deficits and those that have or have had socialist governments also received higher scores. Programs in which a government was the principal recipient received significantly lower scores than those with civil society, private sector or multilateral recipients. Malaria programs were $12.9 \%$ less likely than HIV/AIDS or tuberculosis programs to receive an A. In addition, evaluation scores were slightly higher in countries with higher prevalence rates for the target disease of the program (Radelet and Siddiqi, 2007).

Countries with stronger health systems and larger numbers of trained health workers were more likely to have successful programs. This suggests that the Global Fund needs to ensure greater oversight in countries with weaker systems and capacity, and underscores the importance of building strong health systems rather than focusing narrowly on short-term targets. However, evaluation scores were lower in programs where there were many other donors. This may have been due to the greater administrative and management burden placed on recipients when there are multiple donors. Alternatively, it may indicate that the incentives for strong performance are weaker when recipients have many funding alternatives (Radelet and Siddiqi, 2007).

The Global Fund's country coordination mechanism has been criticized for focusing on government actors and not including people with HIV/AIDS (Gonzalves 2004; McKai 2004). Faith-based organizations in host countries have also not been included in country coordination mechanisms to the degree that they would like, often due to a lack of information from governments, a lack of access to guidelines for funding proposals and a need for assistance in preparing funding proposals (Lee et al., 2002).

The Center for Global Development convened a high-level independent Working Group to help the new Executive Director of the Global Fund define the major tasks that require attention, and provided specific recommendations for action. The Working Group consisted of 21 members, including relevant experts in government, civil society organizations, foundations, academia, private sector companies and disease-based partnership initiatives. Some of the Working Group's key recommendations were: (1) Convene a "Heads of Agencies Group" with the Director General of the WHO, the Executive Director of UNAIDS, and the President of the 
World Bank to jointly tackle key problems in technical assistance, procurement, monitoring, evaluation and other key issues; (2) Work with other agencies to develop an information market for technical assistance, building on existing mechanisms with UNAIDS, the Stop TB Partnership and Roll Back Malaria; (3) Provide early warning information on country programs to recipients, CCM members, governments, international partners and key NGO groups so that actions can be taken quickly to get programs back on track; (4) Commission a management audit of the Secretariat, consider hiring additional Portfolio Managers and consider shifting from one portfolio manager per country to teams of two or three working across countries; (5) Hire a full-time professional fund raising team, led by a senior professional and comprised of experts with diverse skills to work with traditional, non-traditional and private sector donors; (6) Make the Executive Director a nonvoting member of the Board so that the experiences and insights of the Executive Director and the Secretariat are more fully reflected in Board discussions (Radelet 2006).

In its 2007 study of funding practices, the Center for Global Development made the following recommendations to the Global Fund: (1) keep the focus on funding gaps; (2) re-examine strategies to build local capacity; (3) simplify procedures for good performers; and (4) publicly disclose data (Oomman et al., 2007).

A 2007 external evaluation of the Global Fund's Local Funding Agent system concluded that the system should be maintained, but needs to be improved. The evaluation found that the system needs: (1) greater emphasis on health program skills (since few Local Funding Agents have staff with health backgrounds); (2) to implement a quality assurance system to verify the adequacy of Local Funding Agent methods (for example, with respect to documentation of audits); (3) to provide more complete capacity assessments of the organizations that implement programs; (4) to increase the use of in-country partnerships; (5) to implement a comprehensive performance evaluation system for Local Funding Agents; and (6) to create an operational manual or handbook to govern the Local Funding Agent management process (Euro Health Group 2007).

An internal evaluation made similar findings: (1) that there were gaps in Local Funding Agent documentation that failed to meet professional auditing standards; (2) adherence to specific auditing standards needed to be integrated as a requirement in the tendering process; (3) a lack of a consistent management approach; (4) that the Global Fund Secretariat should introduce a systematic performance evaluation system for Local Funding Agents and a handbook; (5) that capacity assessment should extend to sub-recipients, not just principal recipients of funding; (6) the health program skills and experience of Local Funding Agents was inadequate; and (7) that Local Funding Agents needed to develop partnerships with other health-sector players through networking, to have greater access to health sector intelligence and improve coordination with other players (Technical Evaluation Reference Group 2007).

The United States Government Accountability Office (GAO) also conducts reviews of the Global Fund, since the United States contributes funds. In 2007, the GAO review of 80 grant disbursements and 45 grant renewal decisions found that 
they were well documented and that documentation had improved since 2005. The GAO also noted that the Global Fund has begun developing a risk assessment framework to improve the identification of risks that may affect grant implementation, having found that an earlier risk assessment model was inadequate. However, the GAO also found that the lack of a mandatory system of Local Funding Agent performance assessment limits the Global Fund's ability to determine the quality of Local Funding Agent monitoring and reporting (GAO 2007).

\subsection{Bilateral Donors}

Bilateral governmental donations are an important source of financing for HIV/AIDS programs. In 2005, the resources available from all sources totaled USD 8.3 billion, out of which G7/EC and other donor government commitments for HIV/AIDS totaled roughly USD 4.3 billion. Of these donor government commitments, USD 3.5 billion were bilateral commitments and USD 810 million were contributions to the Global Fund. The G7/EC commitments were $85 \%$ of the total donor government commitments for HIV/AIDS (Kates and Lief, 2006).

As we noted earlier, commitments and disbursements are not the same thing. For example, while the United States accounted for $54.4 \%$ of bilateral commitments, it only accounted for $40.6 \%$ of bilateral disbursements in 2005 (see Figs. 7.13 and 7.14).

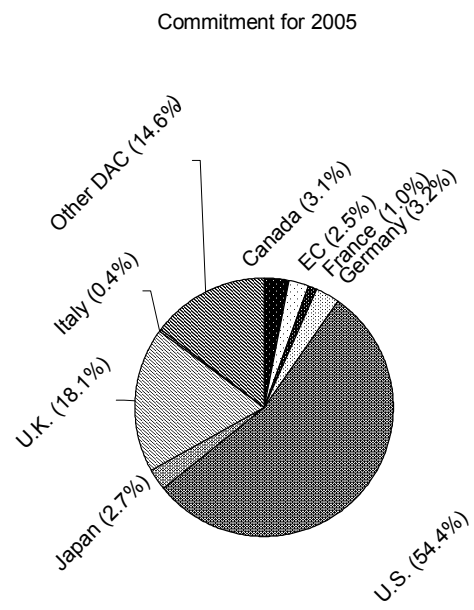

International Assistance for HIVIAIDS in the Developing World, Kaiser Family Foundation, 2006

Fig. 7.13 Origin of resources committed. Source: Kaiser Family Foundation 


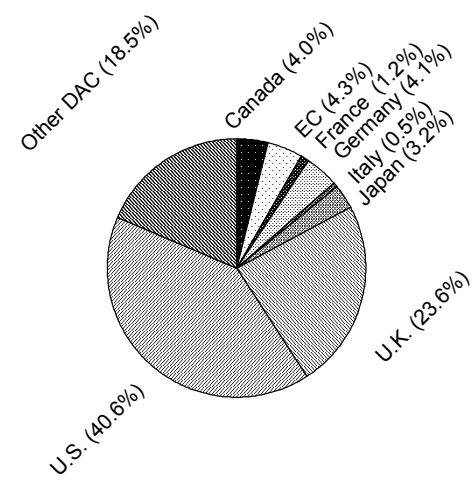

International Assistance for HIVIAIDS in the Developing World, Kaiser Family Foundation, 2006

Fig. 7.14 Actual spending of resources. Source: Kaiser Family Foundation

\section{G7/EC Funding Channels for HIVIAIDS Commitments, by Donor,} 2005

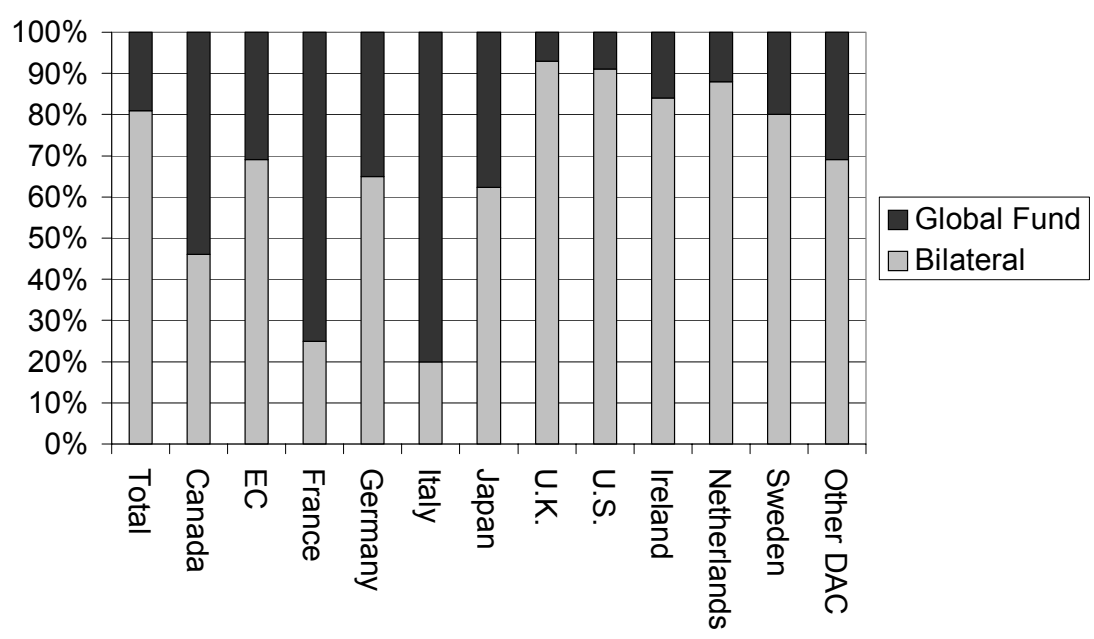

Fig. 7.15 Funding commitments by rich countries for HIV/AIDS. Source: Kates and Lief (2006)

Many donors prefer to channel funding through bilateral programs ( $81 \%$ of G7/ EC commitments), rather than the multilateral channel $(19 \%$ of G7/EC commitments). However, preferences vary from one donor country to the next. For example, at on end of the spectrum, the UK made $93 \%$ of its commitments through bilateral 
channels and 7\% through the Global Fund. At the other end of the spectrum, Italy made $20 \%$ of its commitments through bilateral channels and $80 \%$ through the Global Fund. Canada was in the middle, with $46 \%$ of its commitments through bilateral channels and 54\% through the Global Fund (see Fig. 7.15) (Kates and Lief, 2006).

\subsection{The Role of the Private Sector in Funding Prevention and Treatment}

Engaging the private sector in HIV/AIDS prevention and treatment is increasingly becoming a major focus for governments, advocates and public health practitioners. The private sector, through domestic firms or the foreign direct investment of multinational firms, is a significant source of financing for the prevention and treatment of HIV/AIDS. Private charitable foundations have also become an important source of funding in the fight against HIV/AIDS.

Two issues regarding private sector donors provoke controversy. One is the issue of donations of goods and services in kind by the private sector. Critics argue that such donations impede the ability of recipient governments to build their own infrastructure. Supporters argue that such donations give a boost to local efforts to build infrastructure, provided they take place in close cooperation with recipient governments. A second issue is donor reliability and sustainability, particularly with respect to donations from the private sector (although this issue is also raised regarding other sources of funding). Here, the concern is that host governments will be unwilling to integrate funding for HIV/AIDS into general revenues that support the overall health infrastructure (for example, salaries for medical personnel) unless there is some assurance that the funding will be ongoing (McKinnell 2004).

While the participation of the private sector in addressing the HIV/AIDS pandemic is very important, its efforts need to be coordinated with the other players (governments, donors and NGOs) and the roles of the various players need to be well defined. For example, Oxfam has criticized developed countries and the World Bank for undermining governments' ability to deliver public services by advocating inappropriate private sector projects in health. Oxfam acknowledges that the private sector has a role to play, but argues the private sector cannot provide services on the necessary scale, geared to the needs of all citizens (Oxfam 2006).

\subsubsection{Incentives for Companies to Invest in HIV/AIDS Programs}

Companies have an incentive to invest in HIV/AIDS programs due to the impact of the pandemic on enterprise performance. This impact depends on worker attrition due to sickness and death, the corresponding costs to the firm for providing health and sickness benefits, replacement costs to obtain new workers and the 
impact of HIV/AIDS on worker productivity (Ramachandran et al., 2005). At the same time, the health of a country's population may affect inflows of foreign direct investment to low- and middle-income countries (Alsan et al., 2004). The HIV/AIDS pandemic thus creates a catch-22 situation.

HIV/AIDS has clear effects on a company's workforce and its customer base. The literature suggests that skilled workers are most likely to contract the virus, and that these are extremely difficult to replace. Customers, suppliers and investors in a company are also likely to be affected by HIV/AIDS, and this effect is expected to increase as the virus spreads (Bloom et al., 2001). However, a PriceWaterhouseCoopers survey found that only 39\% of organizations in Eastern Africa had HIV/AIDS policies in place (PriceWaterhouseCoopers 2003).

On an individual basis, firms can have a tremendous impact in promoting prevention among employees and their families and providing access to treatment. For example, in Botswana an early and innovative program by Debswana, a diamond mining company that is the country's largest non-government employer, made it the first company to provide free anti-retroviral treatment to employees and their spouses (Center for Global Development 2005). However, as with multilateral organizations such as the World Bank, the IMF, the Global Fund and the $\mathrm{UN}$, it is important to have an overarching framework in order to ensure the adoption of best practices by individual firms and to minimize overlap between the private sector and the other players that are involved in addressing the pandemic. In this regard, there have been some important national and global initiatives. An example of a national initiative is the Commercial Market Strategies (CMS) project, which was a 5-year USAID-funded project (1998-2003). CMS's AIDS treatment brochure articulated the business case for providing ARVs to employees as part of their health care benefits. The key global initiative is the Global Business Coalition on HIV/AIDS (GBC), which has 220 members, headquartered in thirty countries, employing over eleven million people in more than 200 countries and is supported almost entirely by its member companies.

The GBC and Booz Allen Hamilton conducted a baseline survey and interview program to establish a basis to look at the scope and depth of the response being made by the global business community. The study highlighted variations in business response by region, industry and enterprise scale. The study found that business increasingly sees HIV/AIDS as a strategic as well as a social responsibility issue, and manages programs and resources based on bottom line impact (GBC and Booz, Allen, Hamilton 2006).

The data source was the expertise and experiences of 75 GBC member companies across 17 industries that were surveyed in April 2006 and 30 companies who participated in a detailed interview program. The baseline showed business response in the form of an index, on a scale of $0-10$. The index was calculated from the number of companies active in each of 10 global business HIV/AIDS categories of Best Practice AIDS Standard (BPAS), each with five levels of action. The 
75 surveyed companies had an average index score of 4.5. This was equivalent to being active in more than 8 of 10 categories with two actions underway in each. The most active $25 \%$ scored 7.5 and the least active $25 \%$ scored 1.4 . This variation was primarily due to perceived business needs and the length of time the companies had been addressing the HIV/AIDS issue. Of the 10 BPAS categories there are two in which the business response was particularly strong - prevention initiatives and community and government partnerships. Companies had the most difficulty in engaging business associates and suppliers (see Fig. 7.16). The most active industry groups were Food/Beverages, Mining and Minerals and Energy (gas and oil) (GBC and Booz, Allen, Hamilton 2006).

The survey found that developing and implementing a company HIV/AIDS program requires about 3 years to move from concept and strategy to fully operational across the business. Of the surveyed companies, $82 \%$ provided workplace information on HIV/AIDS. However, only $41 \%$ conducted surveys and assessments, suggesting that program design and follow up could be enhanced. With respect to prevention programs, $60 \%$ of the companies had trained peer educators in place and $55 \%$ had expanded prevention programs to the community. Companies

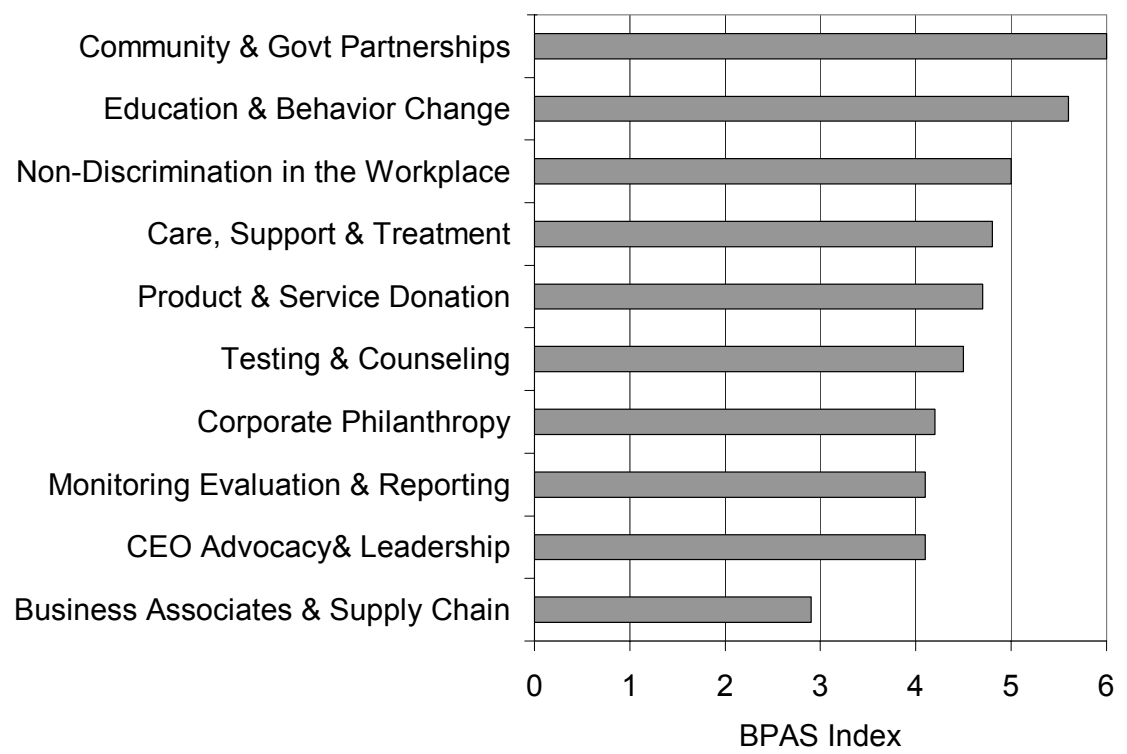

Fig. 7.16 GBC and Booz, Allen, Hamilton survey of company HIV/AIDS programs. Source: GBC and Booz, Allen, Hamilton (2006)

were twice as likely to fully subsidize treatment for employees in high prevalence areas. In parts of Africa with high HIV prevalence, more than $70 \%$ of the companies surveyed were fully subsidizing staff access to HIV treatment. Globally, $36 \%$ of surveyed companies fully subsidize treatment for direct employees and $45 \%$ provided access to treatment for all dependents (GBC and Booz, Allen, Hamilton 2006). 
The GBC survey had several key findings regarding ways to improve the global business community's response to HIV/AIDS. First, there is a need to develop strategies to work closely with suppliers and business associates to expand the network of business engagement. Second, there is a need to partner with NGOs, community, and local government to develop and fund programs and initiatives with greater reach. Third, companies should extend confidential testing and treatment programs, including monitoring of testing participation rates, access to viral load tests and, in high prevalence areas, treatment for dependents and post employment. Fourth, companies should focus on balanced prevention and treatment programs that target behavior change in conjunction with treatment. Fifth, there is a need to increase the role of business in advocacy and to extend programs into emerging markets. In particular, CEOs and senior management should provide leadership to dispel myths and stigma, break down workplace barriers and influence community change. In this regard, the GBC study concluded that the private sector can enhance their response to HIV/AIDS by treating it like any other disease and integrating responses into broader packages supporting health and well-being. Employment contracts and health benefits packages should include HIV as a normal component rather than an exception. Rather than isolating HIV/AIDS, interventions should be part of a comprehensive health system for employees and the broader community (GBC and Booz, Allen, Hamilton 2006).

The GBC study recommends that an HIV/AIDS response be a core component of an overall business strategy, whether the response takes the form of cause-related marketing, co-investments with governments on HIV programs or comprehensive workplace policies. Proactive action on AIDS can help position a company as an overall market leader and will also help sustain markets and serve a need in countries like India and China, with rapidly growing young, sexually active middleclass populations (GBC and Booz, Allen, Hamilton 2006).

\subsubsection{Market-Based Initiatives to Increase Private Sector Funding}

In addition to direct company participation in prevention and treatment programs, there have been efforts to create market-based incentives for the private sector to donate more funds to combating HIV/AIDS. The most notable example is Product RED, an economic initiative designed to deliver a sustainable flow of private sector money to the Global Fund to Fight AIDS, Tuberculosis and Malaria. This initiative was announced at the World Economic Forum Annual Meeting in 2006 by Bono and Bobby Shriver. With Product RED, the world's leading companies made a commitment to channel a portion of their profits from sales of speciallydesigned products to the Global Fund to support AIDS programs for women and children in Africa. 
Another market-based initiative for the private sector is "social marketing". Population Services International (PSI), a nonprofit organization based in Washington, DC., created a comprehensive Corporate AIDS Prevention Program for companies seeking to fight HIV/AIDS in the workplace. PSI, a large aid contractor, uses commercial marketing strategies to promote health products, services and healthy behavior in low-income and vulnerable populations in 70 developing countries. Products and services are sold at subsidized prices rather than being provided free of charge. The logic behind social marketing is that charging money will enhance the perceived value of products and services, increase the likelihood of use, and motivate commercial sector involvement. However, the notion that fee needs to be charged for HIV treatment in order for the recipients to see "value" in the drugs has been discredited.

Arata Kochi, the director of the World Health Organization's malaria program, has concluded that the social marketing approach is not an effective means to expand the use of mosquito nets to prevent malaria. Using the social marketing approach, mosquito nets were sold through local shops at subsidized prices, with donors underwriting the losses and paying consultants to come up with brand names and to advertise the nets. The social marketing approach was also used to distribute condoms and oral rehydration salts. However, it was revealed that the United States Agency for International Development (USAID) was spending $95 \%$ of its malaria budget on consultants and 5\% on goods like nets, drugs and insecticide. Experiences in Kenya helped to persuade the WHO to change its policy. A 5-year study of 40 health districts revealed that a PSI social marketing scheme for malaria nets only increased coverage from $7 \%$ of the population to about $21 \%$ between 2002 and 2006. In contrast, when the health ministry got a grant from the Global Fund that allowed it to hand out 3.4 million free nets in 2 weeks, coverage rose to $67 \%$, and distribution became more equitable. Under social marketing, the richest of the poor had 38\% coverage, while the poorest of the poor had only $15 \%$. After the distribution of free nets, they were about equal and deaths of children dropped $44 \%$. Free distribution was also cheaper. With consultant fees, transportation, advertising and shipping, social marketing added about USD 10 to the cost of each net beyond the USD 5 to USD 7 that manufacturers charged. Even with payments to volunteers, the added cost of free distribution was only about USD 1.25 per net (Kyama and McNeil, 2007).

Médecins Sans Frontières (MSF) has criticized donors for proposing to continue having patients make a financial contribution to the cost of ARV treatment in populations where incomes are barely adequate for people to feed themselves (Médecins Sans Frontières 2005). AIDS patients need to receive treatment their entire lives without interruption in order to avoid death or creating drug-resistant mutations of HIV. Requiring patients (who do not have enough money for food) to pay for treatment reduces the effectiveness of ARV treatment, reduces adherence and decreases survival rates. Even where ARV treatment is free of charge, where countries define AIDS care narrowly many direct treatment costs must be covered by patients. For example, the high cost of laboratory tests can deter patients from 
monitoring the effectiveness and side effects of ARV treatment. A related problem is the cost of treatment for opportunistic infections (such as pneumonia), which may bankrupt patients before they even start ARV treatment. Other costs, such as consultation or hospital fees, can also constitute a barrier to treatment for patients in developing countries. As a result, MSF has recommended that major international donors such as the Global Fund, PEPFAR, and the World Bank should require recipients to provide ARV treatment and other essential elements of AIDS care without patient contributions, and to slightly increase funding to include these complementary costs (Philips 2007).

The World Bank President, former US trade representative Robert Zoellick, has called on the bank's 185 member nations to give the private sector a bigger role in development (Reuters 2007). With respect to the World Bank's AIDS programs, as well as other health-related issues, careful thought will have to be given to the appropriate role for the private sector, particularly the failure of social marketing to achieve adequate and equitable coverage in poor populations.

The experience of the private sector thus far indicates that the business response to the AIDS pandemic needs to be standardized and coordinated with the activities of other players, notably national governments, NGOs and multilateral institutions. While some companies limit their response to donations of money, goods and services, others have taken a more proactive approach by implementing prevention and treatment programs for their employees and, in some cases, the dependents of employees. This proactive approach is particularly useful in areas with high prevalence rates and poor public health care infrastructure.

Global multinational companies are in a position to use their influence with suppliers and other business associates to expand the use of best practices, particularly with respect to prevention and treatment programs. In this regard, the GBC plan to review the state of business and AIDS annually and to use the results of these assessments to adapt the Best Practice AIDS Standard is to be commended. The GBC study notes that companies have addressed child labor, wage equity and occupational safety through their supply chains, including distributors, business associates and small and medium enterprises. However, this network of global suppliers has been a weak link in the AIDS response. If tapped, the reach of employee and community networks could make a tremendous impact in mobilizing communities around HIV prevention and treatment. Similarly, enhanced supply chain practices promoting youth education and gender equity can help to address underlying social factors that contribute to the spread of HIV/AIDS (GBC and Booz, Allen, Hamilton 2006).

The further standardization of best practices would be a useful next step. The International Standards Organization (ISO) certification process that is currently used to improve business processes could serve as a model. The ISO has specific standards for the automotive industry and has specific standards for environmental processes. While these standards are voluntary, many multinational companies require their suppliers to be ISO-certified. The creation of specific ISO standards for HIV/AIDS policies, or for company health policies more generally, would be a 
useful vehicle for standardizing best practices and expanding the adoption of best practices to suppliers. As with ISO, the standards could be voluntary, but major multinationals could require their suppliers to get certified in order to qualify as suppliers.

\subsubsection{Funding from Private Charitable Foundations}

Private charitable foundations have become a significant source of funding, research and political leadership in fighting HIV/AIDS. In this section, we examine the HIV/AIDS activities of three US foundations: the Bill \& Melinda Gates Foundation, the Kaiser Family Foundation and the William J. Clinton Foundation. It is notable that these foundations have largely avoided overlap in the nature of their operations related to HIV/AIDS, by specializing in addressing different needs. The first two foundations have also collaborated closely.

\subsubsection{Bill \& Melinda Gates Foundation}

As of 31 December 2006, the Bill \& Melinda Gates Foundation had net assets totaling USD 30 billion, which it uses to fund global development and global health initiatives. The mission of the foundation's Global Health Program is to encourage the development of lifesaving medical advances and to help ensure they reach the people who are disproportionately affected. The foundation is guided by the belief that all lives, no matter where they are lived, have equal value. With respect to global health, the foundation focuses its funding in two main areas: (1) access to existing vaccines, drugs and other tools to fight diseases common in developing countries; and (2) research to develop health solutions that are effective, affordable and practical. In developing countries, the foundation supports efforts to prevent and treat diseases and conditions that meet three criteria: (1) they cause widespread illness and death in developing countries; (2) they represent the greatest inequities in health between developed and developing countries; and (3) they receive inadequate attention and funding. HIV/AIDS is one of the foundation's priority diseases. To slow the global spread of HIV, the foundation supports the development of vaccines and other tools and strategies with the potential to prevent tens of millions of infections and deaths. The foundation also funds comprehensive initiatives that include both prevention and treatment (http://www.gatesfoundation. org/GlobalHealth/).

The Bill \& Melinda Gates Foundation's primary focus with respect to HIV/AIDS is on prevention. Illustrative examples of the programs funded by the foundation are: (1) Avahan (which means Call to Action in Sanskrit), an AIDS prevention initiative established in India in 2003, to which it has committed USD 258 million; 
(2) the Global HIV Prevention Working Group, an international panel of experts; and (3) the Global HIV Vaccine Enterprise. Through the Avahan program, the foundation is working to expand access to effective prevention in the six states with India's highest infection rates and along the nation's major trucking routes. The Working Group is an international panel of more than 50 leading public health experts, clinicians, researchers and people affected by HIV/AIDS. It is coconvened by the Henry J. Kaiser Family Foundation and the Bill \& Melinda Gates Foundation. The Global HIV Prevention Working Group has developed reports and other materials about critical HIV prevention issues, such as scaling up the combined use of proven prevention strategies (male circumcision, AIDS education, condoms, HIV testing and prevention of mother-to-child transmission) in order to cut the number of projected new infections to 2015 in half (Global HIV Prevention Working Group 2007).

The Global HIV Vaccine Enterprise is an international alliance of independent organizations dedicated to accelerating the development of an HIV/AIDS vaccine through collaborative research efforts. The Bill \& Melinda Gates Foundation serves as interim chair and funds vaccine research. In July 2006, the Bill \& Melinda Gates Foundation funded 16 grants totaling USD 287 million to create an international network of collaborative research consortia focused on accelerating the pace of HIV vaccine development (http://www.gatesfoundation.org).

\subsubsection{Henry J. Kaiser Family Foundation}

The Kaiser Family Foundation is a non-profit, private operating foundation focusing on the major health care issues facing the United States, but has a growing role in global health. The foundation has an endowment of over half a billion dollars and an operating budget of over USD 40 million per year. Unlike grant-making foundations, Kaiser develops and runs its own research and communications programs, sometimes in partnership with other non-profit research organizations or major media companies. This foundation focuses on three areas of activity: (1) Producing policy analysis and research; (2) Operating a large-scale health news and information service on the web and a series of specialized websites; and (3) Developing and helping to run large-scale public health information campaigns in the United States and around the world, through direct partnerships with major media companies. The current focus of the latter is on HIV/AIDS, with an emphasis on reaching young people (http://www.kff.org/about/index2.cfm).

\subsubsection{William J. Clinton Foundation}

The William J. Clinton Foundation is President Bill Clinton's vehicle for strengthening the capacity of people in the United States and throughout the world to meet the challenges of global interdependence. One of the foundation's main initiatives is focused on HIV/AIDS. In 2007, the foundation helped to negotiate major price reductions for 66 developing countries for 16 medicines critical to fighting HIV/ 
AIDS, in an agreement with pharmaceutical manufacturers (see Chap. 9). These countries together have $90 \%$ of AIDS cases in the developing world. The foundation's HIV/AIDS Initiative (CHAI) has also involved political leadership from President Clinton to reduce fear and ignorance of the disease and to discourage discrimination. Donations are the primary source of revenue for the foundation, making up USD 109,730,002 of the USD 112,687,167 in revenue for 2006 (http:// www.clintonfoundation.org).

The Clinton Foundation also funds access to treatment and information. It has committed USD 38 million to fund a 3-year program to ensure all HIV-positive children in Kenya receive treatment. The funds would pay for a public awareness campaign and purchase anti-retroviral drugs to rapidly scale up the number of infected children under treatment from 2009 to 2010. Half all HIV-positive children in Kenya die before their second birthday; $50 \%$ of those die because they are not provided with treatment. Anti-retroviral therapy would increase the life expectancy to 27 years. Of an estimated 102,000 HIV-positive children, 60,000 are in need of treatment and only 13,000 are on life-saving anti-retroviral therapy. A survey commissioned by the Kenyan Ministry of Medical Services showed that $61 \%$ of mothers and caregivers were unaware of the availability of HIV testing for children and that only $12 \%$ had taken their children for HIV testing (Ndegwa 2007).

\subsubsection{Private Sector Collaboration}

There is also collaboration among private firms, private foundations and host governments. For example, an innovative model for fighting HIV/AIDS in Africa is being piloted in Botswana through a public-private partnership involving the government of Botswana, the Bill \& Melinda Gates Foundation and Merck \& Co., Inc. The partnership is intended to help Botswana achieve an "AIDS-Free Generation by 2016" by expanding prevention, supporting treatment, increasing counseling and testing and empowering communities (Center for Global Development and Merck 2007).

\subsection{Implications for Other Global Diseases}

The main focus of this chapter has been on multilateral financial institutions. However, it is important to note the role of other financial donors, notably bilateral governmental arrangements. Private actors and NGOs also make significant contributions to addressing the global AIDS pandemic. As important as it is to marshal the resources of numerous governmental and non-governmental agencies, the multiplicity of donors involved in the AIDS epidemic, together with a multiplicity of donor requirements, is a significant issue in seeking to expand prevention and treatment programs. 
National political leadership is a crucial part of any HIV/AIDS strategy. In many countries, statements made by politicians who make decisions on resource allocation have been appalling. In South Africa, Tshabalala-Msimang, the health minister, shares South African President Mbeki's rejection of the international scientific consensus that AIDS is caused by the HIV. The health minister has also criticized the use of standard anti-retroviral drugs to treat AIDS, recommending instead that South Africans with AIDS follow a diet of beetroot, garlic, olive oil and African potato. In a recent South African population survey, a quarter of the population said they didn't believe in a link between HIV and AIDS (Wilson 2007). Figure 7.17 reveals the impact of misinformation on South Africans perceptions regarding the sources of HIV transmission.

\section{Percent of South African Adults Who Think AIDS Can Be Contracted From....}

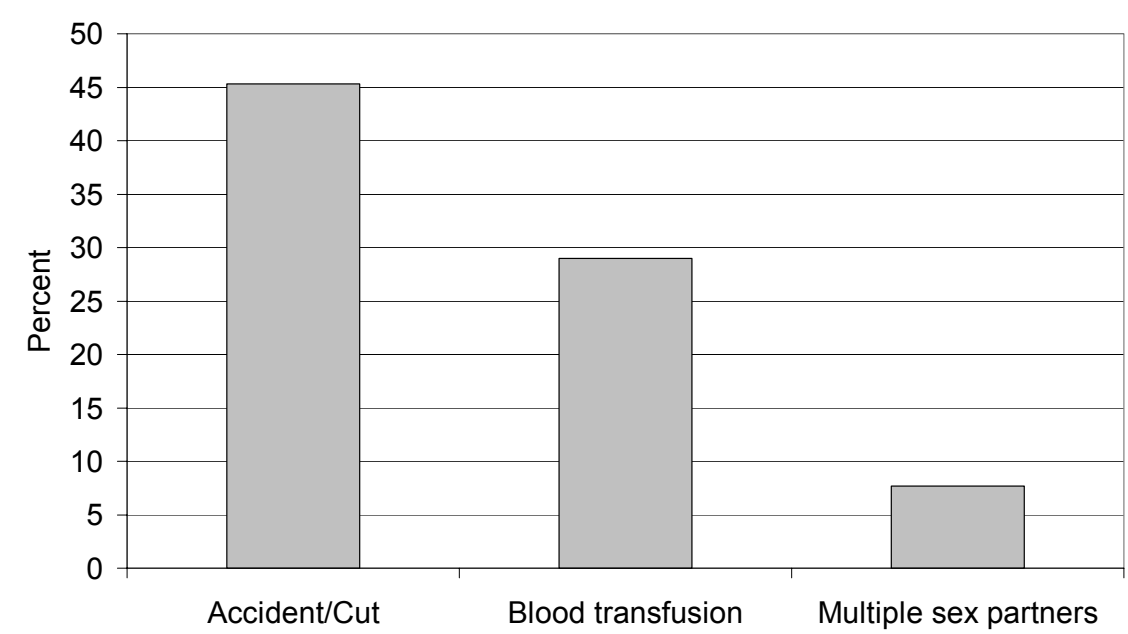

Fig. 7.17 Confusion in South Africa regarding sources of HIV transmission. Source: Wilson (2007)

The head of the Catholic Church in Mozambique, Maputo Archbishop Francisco Chimoio, has told the media he believes some European-made condoms are infected with HIV deliberately. He has also claimed some anti-retroviral drugs were also infected "in order to finish quickly the African people". The Catholic Church opposes any use of condoms, advising instead fidelity within marriage or sexual abstinence. About $17.5 \%$ of Mozambicans are Catholic and roughly $16.2 \%$ of Mozambique's population is HIV positive (BBC News 2007a). These lapses in political leadership highlight the need to incorporate political leadership into AIDS programs that are funded by multilateral, bilateral and private sector donors.

Multilateral institutions, such as the World Bank, the IMF and the Global Fund, and bilateral donors, including NGOs and national governments, need to coordinate and harmonize their policies and financing conditions further in order to reduce 
the administrative burden on recipients and in order to avoid imposing conflicting conditions on recipients. Donors also need to be careful with respect to the role assigned to the private sector in delivering aid, in order to avoid the unnecessary diversion of funds away from the core goal of health care. In this regard, the experience to date suggests that social marketing is less effective and less equitable than the free provision of goods and services. Particularly in the case of fastmoving infectious diseases, equitable and effective distribution should be paramount, since such diseases are unlikely to respect socio-economic boundaries, as the experience with HIV/AIDS and malaria has demonstrated. In particular, donors should not impose requirements to use patented medicines in place of cheaper, generic alternatives.

The global business community has an important role to play in addressing global diseases. There are several key lessons that arise from the GBC's experience with HIV/AIDS. First, it is important to integrate health issues into overall business strategy, particularly since it takes about 3 years to fully implement such strategies. Second, there is a need to standardize best practices on a more systematic basis and to create incentives for those best practices to be adopted by suppliers and business partners of global companies. In this regard, the creation of ISO standards for company health policies would be extremely useful, particularly for fastmoving global infectious diseases that have the potential to cause widespread economic damage and human suffering, such as avian influenza and SARS.

The global response to the HIV/AIDS pandemic has highlighted the need to strengthen health care infrastructure in developing countries. There is a concern that the high profile given to the HIV/AIDS pandemic may have diverted funds away from other important health issues (England et al., 2007). In Chap. 4 we concluded that the focus on HIV/AIDS is justified, but it is important to address the HIV/AIDS pandemic in a way that strengthens the ability of national governments and multilateral organizations to address health concerns more generally. The following chapter examines the role of global health organizations in the HIV/AIDS pandemic, with a particular focus on the World Health Organization, which is the multilateral institution that is charged with addressing global health issues.

\section{References}

Alsan M, Bloom DE, Canning D (2004) The Effect of Population Health on Foreign Direct Investment. NBER Working Paper No. 10596, http://papers.nber.org/papers/w10 596. Accessed 15 August 2005

BBC News (2007a) Shock at Archbishop Condom Claim. http://news.bbc.co.uk/2/hi/ africa/7014335.stm. Accessed 26 September 2007

BBC News (2007b) HIV Treatment 'Failing' in Africa. http://news.bbc.co.uk/2/hi/africa/ 7046545.stm. Accessed 16 October 2007

Bloom DE, Mahal A, River Path Associates (2001) HIV/AIDS and the Private Sector - A Literature Review. http://www.psp- one.com/content/resource/detail/2612/. Accessed 5 June 2006 
Center for Global Development (2005) Private Sector Responses to HIV/AIDS: The Case of Debswana, Botswana's Diamond Company. http://www.cgdev.org/content/calendar/ detail/4258/. Accessed 15 June 2006

Center for Global Development and Merck (2007) Can Public-Private Partnerships Help Stop AIDS in Africa? Lessons from Botswana.http://www.cgdev.org/content/calendar/detail/ 13758/. Accessed 5 September 2007

Dekay S (2004) Funding the Response to AIDS: Why are Donors not Working Together? 15th Annual International AIDS Conference, Bangkok http:/www.kaisernetwork.org/ health_cast/uploaded_files/071204_ias_funding.pdf. Accessed 5 June 2006

Easterly W (2006) The White Man's Burden. Penguin, New York

ECA Press Release (2003) African Ministers Pronounce on Aid, Trade, Debt, IMF, HIV/AIDS. http://www.uneca.org/eca_resources/press_releases/2003_pressreleases/pressrelease0803.htm. Accessed 25 June 2007

England R, de Lay P, Greener R, Izazola JA(2007) Are we spending too much on HIV? British Medical Journal 334:344-345

Euro Health Group (2007) Global Fund to Fight AIDS, Tuberculosis and Malaria: Evaluation of the Local Fund Agent System. http://www.theglobalfund.org/en/files/links reesources/library/studies/specific_evaluations/GFATM_Evaluation_of_LFA_Report.pdf. Accessed 7 January 2008

GAO (2007) Global Fund to Fight AIDS, TB and Malaria Has Improved its Documentation of Funding Decisions but Needs Standardized Oversight Expectations and Assessments. http://www.theglobalfund.org/en/files/links_resources/library/studies/integrated_evaluations/ d07627.pdf. Accessed 7 January 2008

GBC and Booz, Allen, Hamilton (2006) The State of Business and HIV/AIDS. http:// www.businessfightsaids.org/atf/cf/\% 7B4AF0E874-E9A0-4D86-BA28-96C3BC31180A\% 7D/ The $\% 20$ State $\% 20$ of $\% 20$ Business $\% 20$ and\%20HIVAIDSFINAL.pdf. Accessed 19 October 2007

Global Fund (2003) The Framework Document of the Global Fund to Fight AIDS, Tuberculosis and Malaria. http://www.theglobalfund.org/en/files/publicdoc/Framework_uk. pdf. Accessed 5 October 2007

Global HIV Prevention Working Group (2007) Bringing HIV Prevention to Scale: An Urgent Global Priority. http://www.globalhivprevention.org/pdfs/PWG-HIV_prevention report_FINAL.pdf. Accessed 15 November 2006

Gonzalves G (2004) Funding the Response to AIDS: Why are Donors not Working Together? 15th Annual International AIDS Conference, Bangkok, 12 July 2004, http:// www.kaisernetwork.org/health_cast/uploaded_files/071204_ias_funding.pdf. Accessed 5 June 2006

Hanlon J (1999) Pound of flesh: Joseph Hanlon Reports on How Local People have Wised up to a Huge International Hoax. New Internationalist, March 1999, http:// findarticles.com/p/articles/mi_m0JQP/is_310/ai_30471475. Accessed 6 October 2007

Hanlon J (2006) Donor Concern over IMF Cap on Aid Increases. http://www.open.ac. uk/technology/mozambique/. Accessed 6 October 2007 
IMF (2005) The IMF's Role in the Fight Against HIV/AIDS. http://www.imf.org/ external/np/exr/facts/hivaids.htm. Accessed 16 October 2007

Kaberuka D (2007) The New International Aid Architecture: New Players, New Challenges, Old Problems? http://www.ideas4development.org/the-new-international-aidarchitecture-new-players-new-challenges-old-problems/en/. Accessed 20 October 2007

Kasheeka EB, Bicego G, Gorgens-Albino M, Kemerer V, Nzima M (2006) Strengthening Partnerships in HIV Monitoring and Evaluation: How Joint Missions Build and Strengthen Partnerships to Support the Realization of National M\&E systems. World Bank Working Paper, http://www-wds.worldbank.org. Accessed 5 August 2007

Kates J, Lief E (2006) International Assistance for HIV/AIDS in the Developing World: Taking Stock of the G8, Other Donor Governments, and The European Commission. Kaiser Family Foundation, Center for Strategic and International Studies/UNAIDS, data. unaids. org/pub/BaseDocument/2006/20060731-KFF-international-assistance_en.ppt.

Accessed 6 November 2007

Kyama R, McNeil DG Jr (2007) Distribution of Nets Splits Malaria Fighters. www. nytimes.com. Accessed 9 October 2007.

Lee C et al. (2002) Global Fund Responsiveness to Faith-based Organizations. http:// www.aidspan.org/documents/other/gfo33.pdf. Accessed 19 October 2007

Love B, Pattanaik S (2007) IMF must Adapt and Downsize or die, New Boss Says. Reuters, 2 October 2007

Lurie P, Hintzen P, Lowe RA (1995) Socioeconomic obstacles to HIV prevention and treatment in developing countries: The roles of the international monetary fund and the World bank. AIDS 9:539-546

McKai R (2004) Funding the Response to AIDS: Why are Donors not Working Together? 15th Annual International AIDS Conference, Bangkok, 12 July 2004, http:// www.kaisernetwork.org/health_cast/uploaded_files/071204_ias_funding.pdf. Accessed 2 October 2007

McKinnell H (2004) Funding the Response to AIDS: Why are Donors not Working Together? 15th Annual International AIDS Conference, Bangkok, 12 July2004, http://www. kaisernetwork.org/health_cast/uploaded_files/071204_ias_funding.pdf. Accessed 8 October 2007

Médecins Sans Frontières (2005) Access to Healthcare, Mortality and Violence in Democratic Republic of the Congo. http://www.doctorswithoutborders.org/publications/ reports/2005/drc_healthcare_11-2005.pdf. Accessed 20 October 2007

Mwale B (2004) Funding the Response to AIDS: Why are Donors not Working Together? 15th Annual International AIDS Conference, Bangkok, 12 July 2004, http:// www. kaisernetwork.org/health_cast/uploaded_files/071204_ias_funding.pdf. Accessed 19 October 2007

Ndegwa A (2007) Kenya: Clinton Foundation Provides \$38M for Children Living with HIV/AIDS. East Africa Standard, 16 October 2007, http://www.eastandard.net/archives/index. php? $\mathrm{mnu}=$ details $\& \mathrm{id}=1143976044 \& \mathrm{catid}=159 \&$ PHPSESSID $=8 \mathrm{bf} 8 \mathrm{ad} 663240 \mathrm{a} 5985 \mathrm{ae} 1 \mathrm{e} 31$ 4fcb6c0f3. Accessed 23 October 2007 
OECD (2005) The Paris Declaration. http://www.oecd.org/document/18/0, 2340,en_2649_ 3236398_35401554_1_1_1_1,00.html. Accessed 3 October 2007

OECD (2006) Measuring Aid in support of HIV/AIDS control. http://www.oecd.org/ dataoecd/35/52/37266050.pdf. Accessed 23 October 2007

Oomman N, Bernstein M, Rosenzweig S (2007) Following the Funding for HIV/AIDS: A Comparative Analysis of the Funding Practices of PEPFAR, the Global Fund and the World Bank MAP in Mozambique, Uganda and Zambia. http://www.cgdev.org/content/ publications/detail/14569/. Accessed 29 October 2007

Oxfam (2006) In the Public Interest: Health, Education, and Water and Sanitation for all. http://www.oxfam.org/en/policy/briefingpapers/bp_public_internest. Accessed 14 October 2007

Patel P (2004) Funding the Response to AIDS: Why are Donors not Working together? 15th Annual International AIDS Conference, Bangkok, 12 July 2004, http://www.kaisernetwork.org/health_cast/uploaded_files/071204_ias_funding.pdf. Accessed 12 October 2007

Perone P (2006) A Response to Joseph Hanlon's Recent Article, Donor Concern Over IMF Cap on Aid Increases. 7 February 2006, http:/www.imf.org/external/np/vc/2006/ 020706.htm. Accessed 15 October 2007

Philips M (2007) Making AIDS patients pay for their care: Why evidence does not change anything in international donor policies? In: Medicins sans Frontieres (ed) AIDS: Free Access to Treatment, a Public Health Necessity or an Economic Heresy?

Picard A (2007) Quarantine Sought for Harsh TB strain: Variant Poses 'Extreme Risk,' Scientists Say. Globe and Mail, 23 January 2007

PriceWaterhouseCoopers (2003) HIV/AIDS: What is Business Doing? A Survey of the Business Community's Response to HIV/AIDS in Kenya, Tanzania, Uganda and Zambia. http://www.psp-one.com/content/resource/detail/2250/. Accessed 24 October 2007

Radelet S (Chair) (2006) Challenges and Opportunities for the New Executive Director of the Global Fund: Seven Essential Tasks. Center for Global Development, http://www. cgdev.org/content/publications/detail/10948/. Accessed 19 October 2007

Radelet S, Siddiqi B (2007) Global Fund grant programmes: an analysis of evaluation scores. Lancet 369:1807-1813

Ramachandran V, Shah MK, Turner G (2005) HIV/AIDS and the Private Sector in Africa: Evidence from the Investment Climate Survey Data. http://rru.worldbank.org/documents/ PSDBlog/AIDSpaperOct28.pdf. Accessed 19 October 2007

Reuters (2007) World Bank Chief Calls For New Direction For Lender. 21 October 2007

Sidibe M, Ramiah I, Buse K (2006) Alignment, harmonisation, and accountability in HIV/AIDS. Lancet 368:1853-1854

Smith M (2007) To End an Epidemic: A Study of Foreign Aid and HIV/AIDS. International Relations Thesis, New York University

Technical Evaluation Reference Group (2007) Summary Paper on the Evaluation of the Local Fund Agent System. http://www.theglobalfund.org/en/files/links_resources/library/ studies/specific_evaluations/TERG_Summary_Paper.pdf. Accessed 7 January 2008 
UNAIDS (2005) Final Report, Global Task Team on Improving AIDS Coordination Among Multilateral Institutions and International Donors (GTT). UNAIDS, Geneva

UNAIDS (2006) Effectiveness of Multilateral Action on AIDS: Harmonized Support to Scaling up the National Response. Report for 18th meeting of the UNAIDS Program Coordination board. UNAIDS, Geneva

Wilson D (2007) The Evolving HIV Epidemic: What Have We Learned Since the MAP Began? powerpoint presentation, 10 June 2007

World Bank (2003) HIV/AIDS in Central America: The Epidemic and Priorities for its Prevention. World Bank, Washington

World Bank (2005a) The World Bank's Global HIV/AIDS Program of Action. World Bank, Washington

World Bank (2005a) Committing to Results: Improving the Effectiveness of HIV/AIDS Assistance, An OED Evaluation of the World Bank's Assistance for HIV/AIDS Control. http://siteresources.worldbank.org/EXTIEGHIVAIDS/Resources/hiv_complete_report.pdf. Accessed 3 October 2007

World Bank (2006) Reducing HIV/AIDS Vulnerability in Central America: regional HIV/ AIDS situation and response to the epidemic. Working Paper, http://www-wds.worldbank.org/ external/default/WDSContentServer/WDSP/IB/2007/02/02/000020953_20070202121215/ Rendered/PDF/385440ENGLISH01 nalOverview01PUBLIC1.pdf. Accessed 1 October 2007

World Bank (2007) Rwanda Multi-Country Aids Program (MAP): Em-powering Communities, Harmonizing Approaches, Working Paper. http://www-wds.worldbank.org/ external/default/WDSContentServer/WDSP/IB/2007/09/07/000310607_20070907114625/ Rendered/PDF/406520RW0MAP0communities01PUBLIC1.pdf. Accessed 15 October 2007 World Bank (2007a) Our Commitment: The World Bank's Africa Region HIV/AIDS Agenda for Action 2007-2011. http://siteresources.worldbank.org/EXTAFRREGTOPHIVAIDS/ Resources/WB_HIV-AIDS-AFA_2007-2011_Advance_Copy.pdf. Accessed 19 October 2007 